\title{
Closely-Related $\mathrm{Zn}^{\mathrm{II}}{ }_{2} \mathrm{Ln}^{\mathrm{III}}{ }_{2}$ complexes $\left(\mathrm{Ln}^{\mathrm{III}}=\mathrm{Gd}, \mathrm{Yb}\right)$ with
}

\section{either Magnetic Refrigerant or Luminescent Single-Molecule}

\section{Magnet Properties.}

\author{
José Ruiz, ${ }^{\dagger}$ Giulia Lorusso, ${ }^{\ddagger}$ Marco Evangelisti, ${ }^{\ddagger}, *$ Juan Manuel Herrera, ${ }^{\dagger}$ Euan $\mathrm{K}$. \\ Brechin $^{\S, *}$, Simon J. A. Pope,$\perp$ Enrique Colacio, ${ }^{\dagger, *}$ \\ 'Departamento de Química Inorgánica, Facultad de Ciencias, Universidad de Granada, \\ Av.Fuentenueva S/N, 18071 Granada (Spain), E-mail: ecolacio@ugr.es. ${ }^{\perp}$ Cardiff School of \\ Chemistry, Cardiff University, Cardiff, CF10 3AT, United Kingdom. ${ }^{\S}$ EaStCHEM School of \\ Chemistry. The University of Edinburgh, West Mains Road, Edinburgh, EH9 3JJ (United \\ Kingdom). E-mail: ebrechin@staffmail.ed.ac.uk. IInstituto de Ciencia de Materiales de Aragón \\ (ICMA), CSIC-Universidad de Zaragoza, Departamento de Física de la Materia Condensada, \\ 50009 Zaragoza, Spain.E-mail: evange@unizar.es.
}

\section{Abstract}

The reaction of the compartmental ligand N,N',N"-trimethyl-N,N"-bis(2hydroxy-3-methoxy-5-methylbenzyl)diethylenetriamine $\left(\mathrm{H}_{2} \mathrm{~L}\right)$ with $\mathrm{Zn}\left(\mathrm{NO}_{3}\right)_{2} \cdot 6 \mathrm{H}_{2} \mathrm{O}$ and subsequently with $\mathrm{Ln}\left(\mathrm{NO}_{3}\right)_{3} \cdot 5 \mathrm{H}_{2} \mathrm{O}\left(\mathrm{Ln}^{\mathrm{III}}=\mathrm{Gd}\right.$ and $\left.\mathrm{Yb}\right)$ and triethylamine in $\mathrm{MeOH}$ using a 1:1:1:1 molar ratio leads to the formation of the tetranuclear complexes $\left\{\left(\mu_{3}-\right.\right.$ $\left.\left.\mathrm{CO}_{3}\right)_{2}\left[\mathrm{Zn}(\mu-\mathrm{L}) \mathrm{Gd}\left(\mathrm{NO}_{3}\right)\right]_{2}\right\} \cdot 4 \mathrm{CH}_{3} \mathrm{OH}$ and $\left\{\left(\mu_{3}-\mathrm{CO}_{3}\right)_{2}[\mathrm{Zn}(\mu-\right.$ $\left.\left.\mathrm{L}) \mathrm{Yb}\left(\mathrm{H}_{2} \mathrm{O}\right)\right]_{2}\right\}\left(\mathrm{NO}_{3}\right)_{2} \cdot 4 \mathrm{CH}_{3} \mathrm{OH}$ (2). When the reaction is performed in the absence of triethylamine, the dinuclear compound $\left[\mathrm{Zn}(\mu-\mathrm{L})\left(\mu-\mathrm{NO}_{3}\right) \mathrm{Yb}\left(\mathrm{NO}_{3}\right)_{2}\right]$ (3) is obtained. The structures of (1) and (2) consist of two diphenoxo-bridged $\mathrm{Zn}^{\mathrm{II}}-\mathrm{Ln}^{\mathrm{III}}$ units connected by two carbonate bridging ligands. Within the dinuclear units, $\mathrm{Zn}^{\mathrm{II}}$ and $\mathrm{Ln}^{\mathrm{III}}$ ions occupy the $\mathrm{N}_{3} \mathrm{O}_{2}$-inner and the $\mathrm{O}_{4}$-outer sites of the compartmental ligand, respectively. The remaining positions on the $\mathrm{Ln}^{\mathrm{III}}$ ions are occupied by oxygen atoms belonging to the carbonate bridging groups and by a bidentate nitrate ion in $\mathbf{1}$ and by a coordinated water molecule in 2, leading to rather asymmetric $\mathrm{GdO}_{9}$ and trigonal dodecahedron $\mathrm{YbO}_{8}$ coordination spheres, respectively. Complex $\mathbf{3}$ is made of acetate-dipohenoxo triply 
bridged $\mathrm{Zn}^{\mathrm{II}} \mathrm{Yb}^{\mathrm{III}}$ dinuclear units where the $\mathrm{Yb}^{\mathrm{III}}$ exhibits an $\mathrm{YbO}_{9}$ coordination environment. Variable temperature magnetization measurements and heat capacity data demonstrate that $\mathbf{1}$ has a large magnetocaloric effect (MCE) with a maximum value of $-\Delta S_{\mathrm{m}}=18.5 \mathrm{~J} \mathrm{~kg}^{-1} \mathrm{~K}^{-1}$ at $T=1.9 \mathrm{~K}$ and $B=7 \mathrm{~T}$. Complexes 2 and 3 show slow relaxation of the magnetization and SMM behaviour under an applied $d c$ field of 1000 Oe. The fit of the high temperature data to the Arrhenius equation affords an effective energy barrier for the reversal of the magnetization of $19.4(7) \mathrm{K}$ with $\tau_{\mathrm{o}}=3.1 \times 10^{-6} \mathrm{~s}$ and 27.0(9) $\mathrm{K}$ with $\tau_{\mathrm{o}}=8.8 \times 10^{-7} \mathrm{~s}$, for 2 and 3, respectively. However, the fit of the full range of temperature data indicates that the relaxation process could take place through a Raman-like process rather than through an activated Orbach process. The chromophoric $\mathrm{L}^{2-}$ ligand is able to act as “antenna” group, sensitizing the NIR Yb ${ }^{\text {III }}$ based luminescence in complexes $\mathbf{2}$ and $\mathbf{3}$ through an intramolecular energy transfer to the excited states of the accepting $\mathrm{Yb}^{\mathrm{III}}$ ion. These complexes show several bands in the 945-1050 nm region corresponding to ${ }^{2} \mathrm{~F}_{5 / 2} \rightarrow{ }^{2} \mathrm{~F}_{7 / 2}$ transitions arising from the ligand field splitting of both multiplets. The observed luminescence lifetimes ( $\left.\tau_{\text {obs }}\right)$ are 0.515 $\mu$ s and $10 \mu$ for $\mathbf{2}$ and 3, respectively. The shorter lifetime for $\mathbf{2}$ is due to the presence of one coordinated water molecule on the $\mathrm{Yb}^{\mathrm{III}}$ centre (and to a lesser extent noncoordinated water molecules) which would favor vibrational quenching via $\mathrm{O}-\mathrm{H}$ oscillators. Therefore, complexes 2 and 3, combining field induced SMM behavior and NIR luminescence, can be considered as dual magneto-luminescent materials.

\section{Introduction}

Lanthanide coordination compounds have attracted much recent attention, in part because of their often aesthetically pleasing structures, but mainly due to their fascinating and potentially applicable magnetic and photo-physical properties. ${ }^{1,2}$ 
Magnetochemists have focused their attention toward lanthanide containing complexes that behave as Single-Molecule Magnets $(\mathrm{SMMs})^{3}$ or low temperature molecular magnetic coolers (MMCs). ${ }^{4}$ SMMs are molecular complexes that can function as singledomain nanoparticles, that is to say, they exhibit slow relaxation of the magnetization and magnetic hysteresis below a blocking temperature $\left(T_{B}\right)$. These chemically and physically fascinating nanomagnets, have been proposed for applications in molecular spintronics, ${ }^{5}$ ultra-high density magnetic information storage ${ }^{6}$ and quantum computing at molecular level. ${ }^{7}$ The driving force behind the enormous increase of activity in the field of SMMs is the prospect of integrating them in nano-sized devices. ${ }^{8}$ The origin of the SMM behaviour is the existence of an energy barrier $(U)$ that prevents reversal of the molecular magnetization when the field is removed, leading to bistability. ${ }^{3}$ To increase the height of the energy barrier and therefore to improve the SMM properties, systems with large magnetic moments and large magnetic anisotropy are required. Lanthanide complexes meet these requirements as the unpaired electrons in the inner $f$ orbitals, which are very efficiently shielded by the fully occupied $5 \mathrm{~s}$ and $5 p$ orbitals and therefore interact very poorly with the ligand electrons, exhibit large and unquenched orbital angular momentum and consequently large intrinsic magnetic anisotropy and large magnetic moments in the ground state. ${ }^{1}$ Isotropic (Gd ${ }^{\mathrm{III}}$-based) MMCs show an enhanced magneto-caloric effect (MCE), which is based on the change of magnetic entropy upon application of a magnetic field, and can potentially be used for cooling applications via adiabatic demagnetisation. ${ }^{4}$ Both lanthanide-based SMMs and MMCs are ideally characterized by a large multiplicity of the ground state, because in the former the magnetization depends on $J$ whereas in the latter the magnetic entropy is related to the spin $s$ by the expression $S_{\mathrm{m}}=R \ln (2 s+1)$. However, the local anisotropy of the heavy $\mathrm{Ln}^{\mathrm{III}}$ ions plays opposing roles in SMMs and MMCs. While highly 
anisotropic $\mathrm{Ln}^{\mathrm{III}}$ ions favour SMM behaviour, MMCs are preferably made of isotropic magnetic ions with weak exchange interactions generating multiple low-lying excited and field-accessible states, each of which can contribute to the magnetic entropy of the system, thus favouring a large MCE. Therefore, polynuclear (and high magnetic density) complexes containing the isotropic $\mathrm{Gd}^{\mathrm{III}}$ ion with weak ferromagnetic interactions between the metal ions have been shown to be appropriate candidates for MMCs. $^{9}$

Recently, we reported the carbonate bridged $\mathrm{Zn}_{2}{ }_{2} \mathrm{Dy}_{2}{ }_{2}$ tetranuclear complex $\left\{\left(\mu_{3}-\mathrm{CO}_{3}\right)_{2}\left[\mathrm{Zn}(\mu-\mathrm{LDy})\left(\mathrm{NO}_{3}\right)\right]_{2}\right\} \cdot 4 \mathrm{CH}_{3} \mathrm{OH}^{10 \mathrm{a}}$ with the compartmental ligand $\mathrm{N}, \mathrm{N}^{\prime}, \mathrm{N}^{\prime}$ trimethyl-N,N”-bis(2-hydroxy-3-methoxy-5-methylbenzyl)diethylene triamine $\left(\mathrm{H}_{2} \mathrm{~L}\right.$, see Figure S1), where the carbonato ligand was generated from the fixation of atmospheric $\mathrm{CO}_{2}$ in basic medium, as has been observed for other carbonate-bridged $\mathrm{Ln}^{\mathrm{III}}$ polynuclear complexes. ${ }^{10 \mathrm{~b}, \mathrm{c}}$ This compound represents a rare example of a lanthanide-containing complex that undergoes a transformation from paramagnetic to high energy barrier SMM under zero-field triggered only by diamagnetic dilution. In this paper, we report two additional examples of tetranuclear complexes, $\left\{\left(\mu_{3}\right.\right.$ $\left.\left.\mathrm{CO}_{3}\right)_{2}\left[\mathrm{Zn}(\mu-\mathrm{L}) \mathrm{Gd}\left(\mathrm{NO}_{3}\right)\right]_{2}\right\} \cdot 4 \mathrm{CH}_{3} \mathrm{OH}$, hereafter named $\mathrm{Zn}_{2} \mathrm{II} \mathrm{GII}_{2} \quad$ (1) and $\left\{\left(\mu_{3}-\right.\right.$ $\left.\left.\mathrm{CO}_{3}\right)_{2}\left[\mathrm{Zn}(\mu-\mathrm{L}) \mathrm{Yb}\left(\mathrm{H}_{2} \mathrm{O}\right)\right]_{2}\right\}\left(\mathrm{NO}_{3}\right)_{2} \cdot 4 \mathrm{CH}_{3} \mathrm{OH}$, hereafter named $\mathrm{Zn}_{2}{ }_{2} \mathrm{Yb}^{\mathrm{III}}{ }_{2}$ (2). The former is isostructural to $\left\{\left(\mu_{3}-\mathrm{CO}_{3}\right)_{2}\left[\mathrm{Zn}(\mu-\mathrm{L}) \mathrm{Dy}\left(\mathrm{NO}_{3}\right)\right]_{2}\right\} \cdot 4 \mathrm{CH}_{3} \mathrm{OH}$ and exhibits ferromagnetic interaction between the metal ions and a large MCE, whereas the latter, $\left\{\left(\mu_{3}-\mathrm{CO}_{3}\right)_{2}\left[\mathrm{Zn}(\mu-\mathrm{L}) \mathrm{Yb}\left(\mathrm{H}_{2} \mathrm{O}\right)\right]_{2}\right\}\left(\mathrm{NO}_{3}\right)_{2} \cdot 4 \mathrm{CH}_{3} \mathrm{OH} \cdot 2 \mathrm{H}_{2} \mathrm{O}$, which has a similar structure minus the coordinated nitrate anions, and presents SMM behaviour and interesting NIR luminescence properties. It is worth to mention that NIR luminescent complexes are of high interest due to their optical, biological and sensor applications. ${ }^{11}$ Complexes $\mathbf{1}$ and 2 were prepared from the reaction of $\mathrm{H}_{2} \mathrm{~L}$ with $\mathrm{Zn}\left(\mathrm{NO}_{3}\right)_{2} \cdot 6 \mathrm{H}_{2} \mathrm{O}$ and subsequently with 
$\mathrm{Ln}\left(\mathrm{NO}_{3}\right)_{3} \cdot 6 \mathrm{H}_{2} \mathrm{O}$ in $\mathrm{MeOH}$ and triethylamine by using a 1:1:1 molar ratio. Colorless and yellow prismatic-shaped crystals of $\mathbf{1}$ and $\mathbf{2}$ suitable for X-ray analysis were slowly grown from the solution. When the reaction is performed in the absence of tryethylamine, then the dinuclear compound $\left[\mathrm{Zn}(\mu-\mathrm{L})\left(\mu-\mathrm{NO}_{3}\right) \mathrm{Yb}\left(\mathrm{NO}_{3}\right)_{2}\right]$, hereafter named $\mathrm{Zn}^{\mathrm{II}} \mathrm{Dy}{ }^{\mathrm{III}}$ (3) was obtained in form of prismatic-shaped yellow crystals. Complex 3, like 2, rare examples of $\mathrm{Yb}^{\mathrm{III}}$ containing complexes showing SMM behavior. ${ }^{12}$ Moreover, $\mathbf{2}$ and $\mathbf{3}$ show NIR luminesce and therefore can be considered as magneticluminescent materials.

\section{Experimental}

General Procedures: Unless stated otherwise, all reactions were conducted in ovendried glassware in aerobic conditions, with the reagents purchased commercially and used without further purification. The ligand $\mathrm{H}_{2} \mathrm{~L}$ was prepared as previously described. ${ }^{13}$

\section{Preparation of complexes}

$\left\{\left(\mu_{3}-\mathrm{CO}_{3}\right)_{2}\left[\mathrm{Zn}(\mu-\mathrm{L}) \mathrm{Gd}\left(\mathrm{NO}_{3}\right)\right]_{2}\right\} \cdot 4 \mathrm{CH}_{3} \mathrm{OH} \quad$ (1) $\quad$ and $\quad\left\{\left(\mu_{3}-\mathrm{CO}_{3}\right)_{2}[\mathrm{Zn}(\mu-\right.$ L) $\left.\left.\mathrm{Yb}\left(\mathrm{H}_{2} \mathrm{O}\right)\right]_{2}\right\}\left(\mathrm{NO}_{3}\right)_{2} \cdot 4 \mathrm{CH}_{3} \mathrm{OH}$ (2). These complexes were prepared from the reaction of $56 \mathrm{mg}(0.125 \mathrm{mmol})$ of $\mathrm{H}_{2} \mathrm{~L}$ in $5 \mathrm{~mL}$ of $\mathrm{MeOH}$ with $37 \mathrm{mg}(0.125 \mathrm{mmol})$ of $\mathrm{Zn}\left(\mathrm{NO}_{3}\right)_{2} \cdot 6 \mathrm{H}_{2} \mathrm{O}$ and subsequently with $0.125 \mathrm{mmol}$ of $\mathrm{Ln}\left(\mathrm{NO}_{3}\right)_{3} \cdot 6 \mathrm{H}_{2} \mathrm{O}$ in $\mathrm{MeOH}$, by using a molar ratio of triethylamine. Colorless and yellow prismatic-shaped crystals of $\mathbf{1}$ and 2, respectively, suitable for X-ray analysis were slowly grown from slow evaporation of the mother liquor.

[Zn( $\left.(\mu-\mathrm{L})\left(\mu-\mathrm{NO}_{3}\right) \mathrm{Yb}\left(\mathrm{NO}_{3}\right)_{2}\right]$ (3). To a solution of $\mathrm{H}_{2} \mathrm{~L}$ (56 mg, $\left.0.125 \mathrm{mmol}\right)$ in $5 \mathrm{~mL}$ of $\mathrm{MeOH}$ were subsequently added with continuous stirring $37 \mathrm{mg}(0.125 \mathrm{mmol})$ of $\mathrm{Zn}\left(\mathrm{NO}_{3}\right)_{2} \cdot 6 \mathrm{H}_{2} \mathrm{O}$ and $56 \mathrm{mg}$ of $\mathrm{Yb}\left(\mathrm{NO}_{3}\right)_{3} \cdot 5 \mathrm{H}_{2} \mathrm{O}(0.125 \mathrm{mmol})$. The resulting pale yellow solution was filtered and allowed to stand at room temperature. After two days, well 
formed prismatic pale yellow crystals of compound were obtained with yields in the range $40-55 \%$ based on $\mathrm{Zn}$.

The purity of the complexes was checked by elemental analysis (see Table S1).

\section{Physical measurements}

Elemental analyses were carried out at the "Centro de Instrumentación Científica" (University of Granada) on a Fisons-Carlo Erba analyser model EA 1108. IR spectra on powdered samples were recorded with a ThermoNicolet IR200FTIR using KBr pellets.

Dc susceptibility and isothermal magnetization curves as weel as ac susceptibility measurements under different applied static fields using an oscillating ac field of 3.5 Oe and ac frequencies ranging from 1 to $1500 \mathrm{~Hz}$ were performed with a Quantum Design SQUID MPMS XL-5 device. Heat capacity measurements were carried out down to 0.3 K and in presence of different applied magnetic fields by using a Quantum Design 14TPPMS, equipped with the ${ }^{3} \mathrm{He}$ cryostat option. These experiments were performed on a thin pressed pellet ( 1 mg) of polycrystalline sample thermalized by $\sim 0.2 \mathrm{mg}$ of Apiezon N grease, whose contribution was subtracted by using a phenomenological expression. UV-Vis spectra were measured on a UV-1800 Shimadzu spectrophotometer and the photoluminescence spectra on a Varian Cary Eclipse spectrofluorometer. All near-IR photophysical data were obtained on a JobinYvon-Horiba Fluorolog-3 spectrometer fitted with a Hamamatsu R5509-73 detector (cooled to $-80{ }^{\circ} \mathrm{C}$ using a C9940 housing). For the near-IR lifetimes the pulsed laser source was a Continuum Minilite Nd:YAG configured for 355 nm output. Luminescence lifetime profiles were obtained using the JobinYvon-Horiba FluoroHub single photon counting module and the data fits yielded the lifetime values using the provided DAS6 deconvolution software. 


\section{Single-Crystal Structure Determination.}

Suitable crystals of 1-3 were mounted on a glass fibre and used for data collection. Data for 1 and 2 were collected at $100 \mathrm{~K}$ with a Bruker AXS APEX CCD area detector equipped with graphite monochromated Mo K $\alpha$ radiation $(\lambda=0.71073 \AA$ ) by applying the $\omega$-scan method. Lorentz-polarization and empirical absorption corrections were applied. Intensity data for compound $\mathbf{3}$ were collected at $100 \mathrm{~K}$ on a Agilent Technologies SuperNova diffractometer (mirror-monochromated Mo K $\alpha$ radiation, $\lambda=0.71073 \AA$ ) equipped with Eos CCD detector. Data collections, unit cell determinations, intensity data integrations, routine corrections for Lorentz and polarization effects and analytical absorption corrections with face index-ing were performed using the CrysAlis Pro software package. ${ }^{14}$ The structures were solved by direct methods and refined with full-matrix least-squares calculations on $F^{2}$ using the program SHELXS97 ${ }^{15}$ integrated in WINGX packet programs. ${ }^{16}$ Anisotropic temperature factors were assigned to all atoms except for the hydrogens, which are riding their parent atoms with an isotropic temperature factor arbitrarily chosen as 1.2 times that of the respective parent. Final $R(F), w R\left(F^{2}\right)$ and goodness of fit agreement factors, details on the data collection and analysis can be found in Table S2. Selected bond lengths and angles are given in Table S3.

\section{Results and Discussion}

Complexes $\mathbf{1}$ and $\mathbf{2}$ were prepared from the reaction of $\mathrm{H}_{2} \mathrm{~L}$ with $\mathrm{Zn}\left(\mathrm{NO}_{3}\right)_{2} \cdot 6 \mathrm{H}_{2} \mathrm{O}$ and subsequently with $\mathrm{Ln}\left(\mathrm{NO}_{3}\right)_{3} \cdot 5 \mathrm{H}_{2} \mathrm{O}\left(\mathrm{Ln}^{\mathrm{III}}=\mathrm{Gd}\right.$ and $\left.\mathrm{Yb}\right)$ and triethylamine in $\mathrm{MeOH}$ using a 1:1:1:1 molar ratio. Colorless prismatic-shaped crystals of $\mathbf{1}$ and $\mathbf{3}$ suitable for X-ray analysis, were slowly grown from the corresponding solutions. As expected, the reaction of $\mathrm{H}_{2} \mathrm{~L}$ with $\mathrm{Zn}\left(\mathrm{NO}_{3}\right)_{3} \cdot 6 \mathrm{H}_{2} \mathrm{O}$ and subsequently with 
$\mathrm{Yb}\left(\mathrm{NO}_{3}\right)_{3} \cdot 6 \mathrm{H}_{2} \mathrm{O}$ in $\mathrm{MeOH}$, in the absence of tryethylamine and using a 1:1:1 molar ratio led to colorless crystals of the compound $\left[\mathrm{Zn}(\mu-\mathrm{L})\left(\mu-\mathrm{O}_{3}\right) \mathrm{Yb}\left(\mathrm{NO}_{3}\right)_{2}\right](3)$.

We begin by discussing the simpler dinuclear complex 3 . This compound is isostructural with two $\mathrm{M}^{\mathrm{II}} \mathrm{Dy}{ }^{\mathrm{III}}\left(\mathrm{M}^{\mathrm{II}}=\mathrm{Ni}\right.$ and $\left.\mathrm{Co}\right)$ complexes previously reported by us ${ }^{10 a, 17}$ and its structure consists of a dinuclear $\mathrm{Zn}^{\mathrm{II}} \mathrm{Yb}^{\mathrm{III}}$ molecule, in which the $\mathrm{Yb}^{\mathrm{III}}$ and $\mathrm{Zn}^{\mathrm{II}}$ ions are bridged by two phenoxo groups of the $\mathrm{L}^{2-}$ ligand and one $\mu$-nitrate anion.

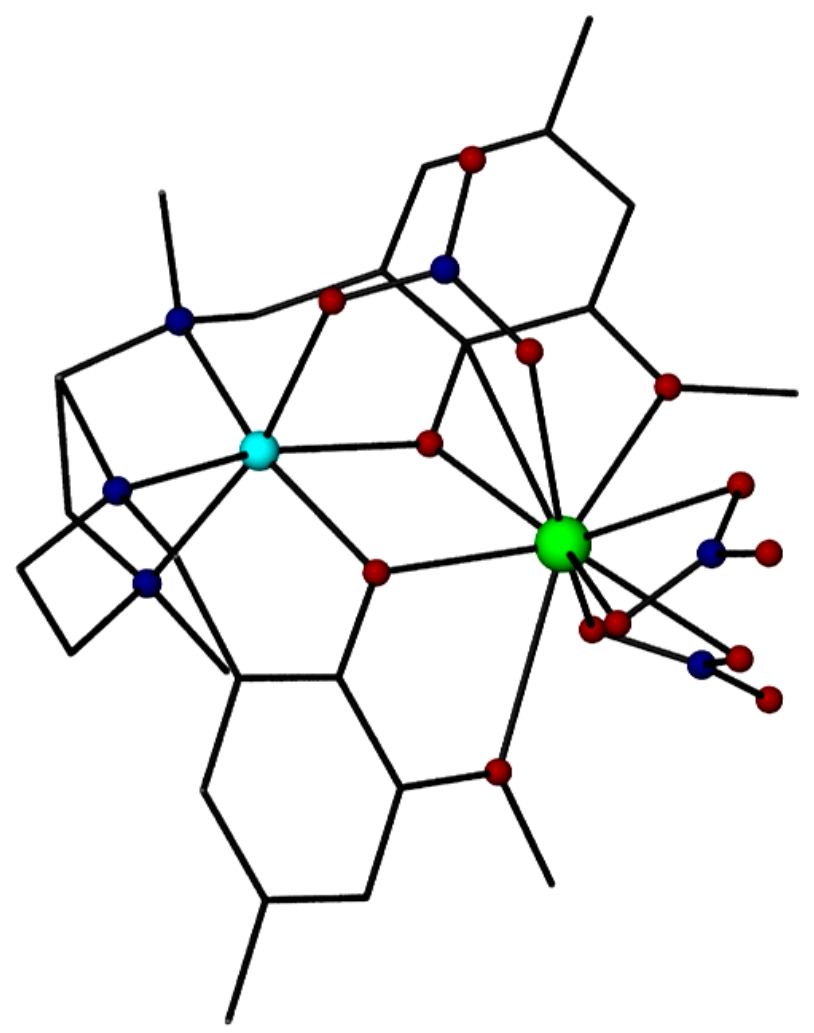

Figure 1.- Perspective view of complex 3 . Colour code: $\mathrm{N}=$ blue, $\mathrm{O}=$ red, $\mathrm{Ni}=$ blue, $\mathrm{Yb}=$ green.

The $\mathrm{L}^{2-}$ ligand coordinates the $\mathrm{Zn}^{\mathrm{II}}$ ions in such a way that the three nitrogen atoms, and consequently the three oxygen atoms, occupy fac positions on the slightly trigonally distorted $\mathrm{ZnN}_{3} \mathrm{O}_{3}$ coordination polyhedron. The $\mathrm{Yb}^{\mathrm{III}}$ ion exhibits a $\mathrm{YbO}_{9}$ coordination sphere which is made by the two phenoxo bridging oxygen atoms, the two methoxy oxygen atoms, one oxygen atom from the nitrate bridging group and four 
oxygen atoms belonging to two bidentate nitrate anions. The Yb-O distances are in the range 2.176-2.571 $\AA$, thus indicating a high degree of distortion in the $\mathrm{YbO}_{9}$ coordination sphere. The calculation of the degree of distortion of the $\mathrm{YbO}_{9}$ coordination polyhedron with respect to an ideal nine-vertex polyhedra, was performed by using continuous shape measure theory and SHAPE software (see Table S4). ${ }^{18}$ The calculation showed that the $\mathrm{YbO}_{9}$ coordination polyhedron is intermediate between several ideal polyhedra, the lowest continuous measures being those of capped square antiprism, $\mathrm{C}_{4 \mathrm{v}}$ (1.45), muffin, $\mathrm{C}_{\mathrm{s}}(1.58)$ and tricapped trigonal prism, $\mathrm{D}_{3 \mathrm{~h}}$ (2.26). The bridging fragment is also rather asymmetric with different bond angles and distances involving the $\mathrm{Yb}^{\mathrm{III}}$ and $\mathrm{Zn}^{\mathrm{II}}$ metal ions. The bridging nitrate group forces the structure to be folded with the average hinge angle of the $\mathrm{Zn}\left(\mu-\mathrm{O}_{2}\right)$ Dy bridging fragment being $14.81^{\circ}$ and the average $\mathrm{Zn}-\mathrm{O}-\mathrm{Yb}$ angle $106.04^{\circ}$. The intra-dinuclear $\mathrm{Zn}-\mathrm{Yb}$ distance is $3.438 \AA$.

Complex $\mathbf{1}$ is isostructural with the previously reported complex $\left\{\left(\mu_{3}-\right.\right.$ $\left.\left.\mathrm{CO}_{3}\right)_{2}\left[\mathrm{Zn}(\mu-\mathrm{L}) \mathrm{Dy}\left(\mathrm{NO}_{3}\right)\right]_{2}\right\} \cdot 4 \mathrm{CH}_{3} \mathrm{OH}^{10 \mathrm{a}}$ and exhibits a centrosymmetric tetranuclear structure (see Figure 2 and Tables S2 and S3 for crystallographic details and selected bond angles and distances) that consists of two diphenoxo-bridged $\left[\mathrm{Zn}(\mu-\mathrm{L}) \mathrm{Gd}\left(\mathrm{NO}_{3}\right)\right]$ dinuclear units connected by two tetradentate carbonato bridging ligands acting with a $\mu_{3}-\kappa^{2}-\mathrm{O}, \mathrm{O}^{\prime}: \kappa-\mathrm{O}^{\prime}: \kappa-\mathrm{O}^{\prime}$ coordination mode, giving rise to a rhomboidal $\mathrm{Gd}(\mathrm{O})_{2} \mathrm{Gd}$ bridging unit with a Gd-O-Gd bridging angle of $115.6^{\circ}$ and two different Gd-O distances of 2.385 and $2.435 \AA$, respectively. 


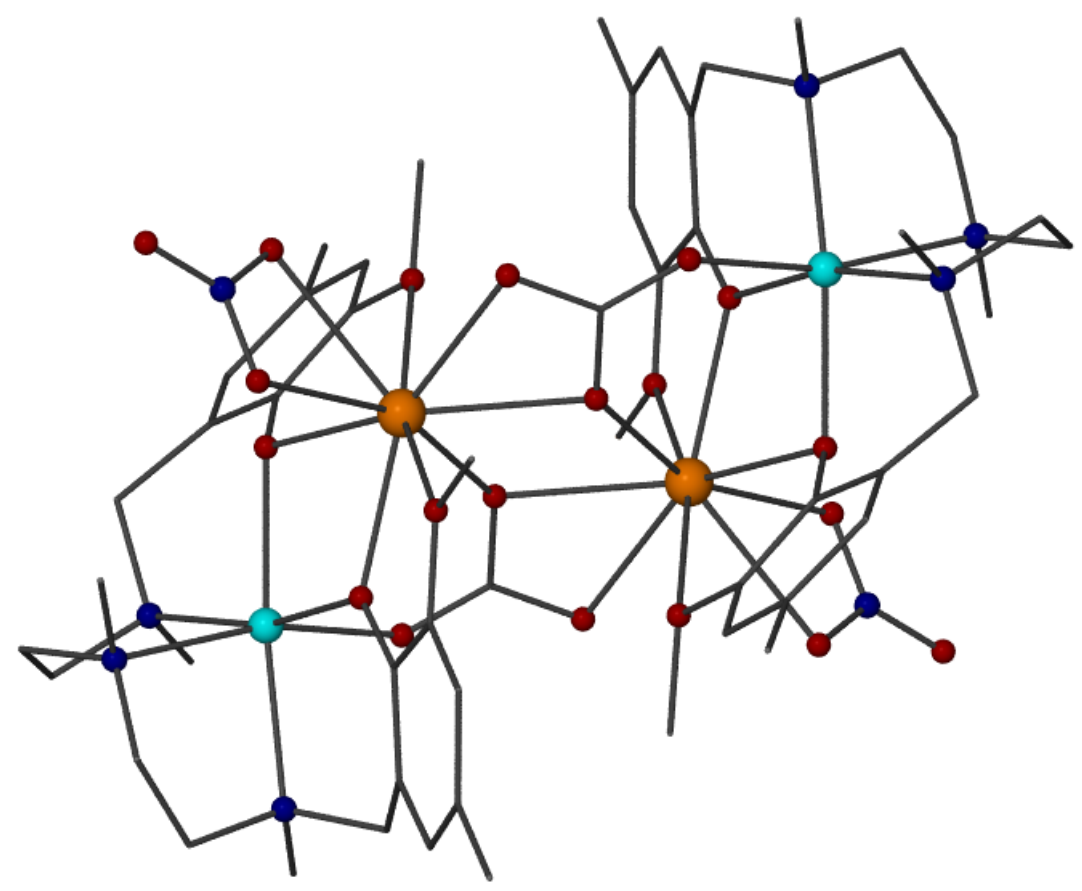

Figure 2. Perspective view of the structure of $\mathbf{1}$. Colour code: $\mathrm{N}=$ dark blue, $\mathrm{O}=$ red, $\mathrm{Zn}=$ light blue, $\mathrm{Gd}=$ orange, $\mathrm{C}$ = grey. Hydrogen atoms and solvent molecules have been omitted for clarity.

The $\mathrm{Gd}^{\mathrm{III}}$ ion exhibits a rather asymmetric $\mathrm{GdO}_{9}$ coordination sphere which is made from the two phenoxo bridging oxygen atoms, the two methoxy oxygen atoms, three oxygen atoms from the carbonato bridging groups and two oxygen atoms belonging to a bidentate nitrate anion. The latter and the chelating part of the carbonato ligand occupy cis-positions in the $\mathrm{Gd}^{\mathrm{III}}$ coordination sphere. The Gd-O distances are in the range 2.302 $\AA-2.564 \AA$. In the bridging fragment, the $\mathrm{Gd}(\mathrm{O})_{2} \mathrm{Gd}$ and carbonato planes are not coplanar, exhibiting a dihedral angle of $26.37^{\circ}$. The intra-tetranuclear Gd $\cdots$ Gd and Gd $\cdots$ Zn distances are $4.079 \AA$ and $3.509 \AA$, respectively.

The tetranuclear molecules $\left\{\left(\mu_{3}-\mathrm{CO}_{3}\right)_{2}\left[\mathrm{Zn}(\mu-\mathrm{L}) \mathrm{Gd}\left(\mathrm{NO}_{3}\right)\right]_{2}\right\}$ are well separated in the structure by methanol molecules of crystallization, the shortest Gd $\cdots$ Gd distance being $8.369 \AA$ A. One of the methanol molecules forms bifurcated hydrogen bonds with 
one of the oxygen atoms of the chelating part of the carbonato ligand and the oxygen atom of a second methanol molecule, with donor-acceptor distances of 2.661 and 2.692 $\AA$, respectively.

The structure of $\mathbf{2}$ is also centrosymmetric and very similar to that of $\mathbf{1}$, but having a water molecule coordinated to the $\mathrm{Yb}^{\mathrm{III}}$ ion instead of a bidentate nitrate ion. This change is probably due to the significant size reduction on going from Gd ${ }^{\mathrm{III}}$ to $\mathrm{Yb}^{\mathrm{III}}$ as a consequence of the lanthanide contraction. In fact the Ln- $\mathrm{O}_{\text {carbonate }}$ distances in the $\mathrm{Ln}(\mathrm{O})_{2} \mathrm{Ln}$ fragment are reduced from $2.435 \AA$ and $2.385 \AA$ in $\mathbf{1}$ to $2.327 \AA$ and $2.302 \AA$ in 2, with the $\mathrm{Yb}-\mathrm{O}-\mathrm{Yb}$ angles in the bridging fragment increasing to $114.0 \AA$. Therefore, the smaller size of the $\mathrm{Yb}^{\mathrm{III}}$ favours the adoption of an eight-coordinated $\mathrm{YbO}_{8}$ coordination polyhedron instead a nine-coordinated one. The degree of distortion of the $\mathrm{YbO}_{8}$ coordination polyhedron with respect to an ideal eight-vertex polyhedra, was calculated by using the continuous shape measure theory and SHAPE software (see Table S4). ${ }^{18}$ The calculation indicated that the $\mathrm{YbO}_{8}$ coordination polyhedron is intermediate between several ideal polyhedra, those being triangular dodecahedron, $\mathrm{D}_{2 \mathrm{~d}}$, biaugmented trigonal prism, $\mathrm{C}_{2 \mathrm{v}}$, and square-antiprism, $\mathrm{D}_{4 \mathrm{~d}}$. Shape measures relative to ideal triangular dodecahedron are however by far the lowest, with a value of 1.54 (see Figure S2). 


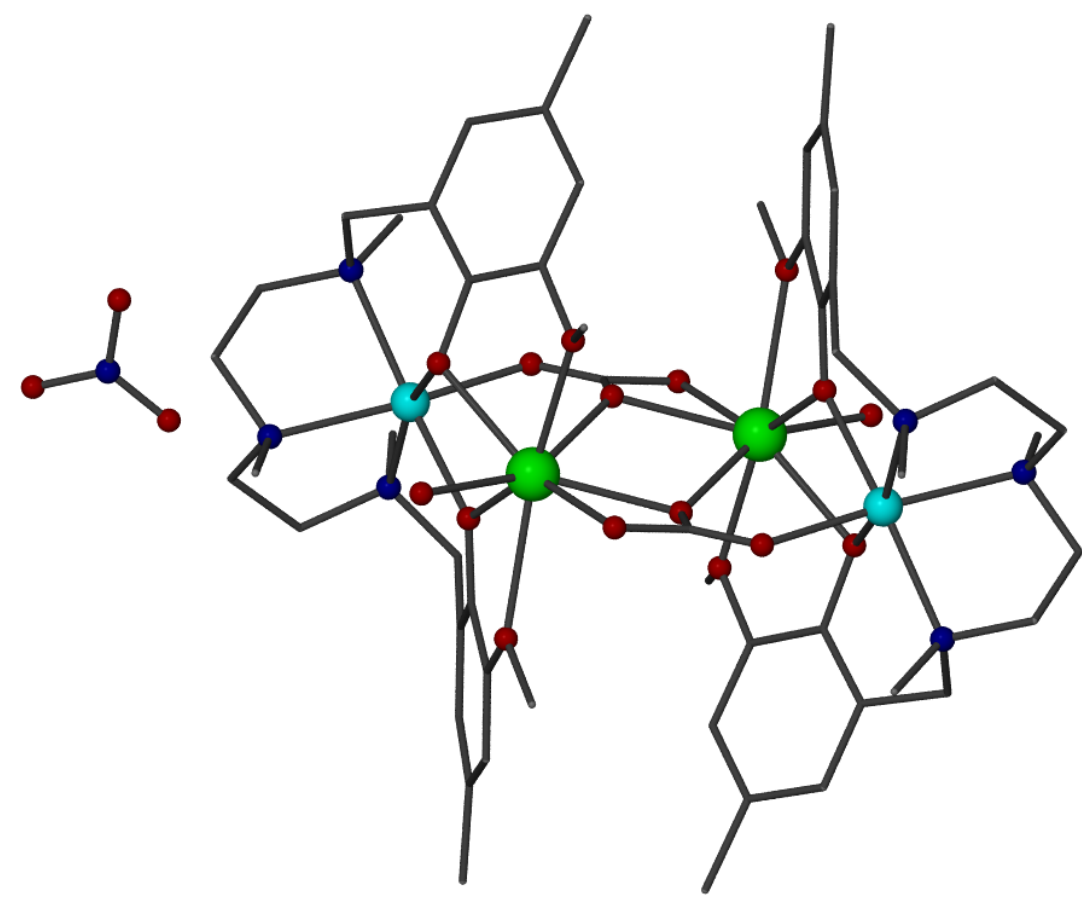

Figure 3. Perspective view of the structure of 2 . Colour code: $\mathrm{N}=$ blue, $\mathrm{O}=$ red, $\mathrm{Zn}=$ light blue, $\mathrm{Yb}=$ green, $\mathrm{C}=$ grey. Hydrogen atoms and solvent molecules have been omitted for clarity

The $\mathrm{YbO}_{8}$ coordination polyhedron can also be described as trigonal bypiramidal, in which the phenol oxygen atoms, are above and below the pentagonal plane. The rest of the structure is similar to that of $\mathbf{1}$, but all distances involving the $\mathrm{Yb}^{\mathrm{III}}$ ions are shorter, as expected. Thus, the Yb-O distances are in the range 2.176 $\AA$-2.571 $\AA$, whereas the intratetranuclear $\mathrm{Yb} \cdots \mathrm{Yb}$ and $\mathrm{Yb} \cdots \mathrm{Zn}$ distances are $3.884 \AA$ and 3.449 $\AA$, respectively. The shortest $\mathrm{Yb}-\mathrm{O}$ distances correspond to the $\mathrm{Yb}-\mathrm{O}_{\text {phenol }}$ and $\mathrm{Yb}-\mathrm{O}_{\text {water }}$ distances. The coordinated water molecules of the tetranuclear $\mathrm{Zn}_{2}{ }_{2} \mathrm{Yb}^{\mathrm{III}}{ }_{2}$ cations, the molecules of methanol, the non-coordinated water molecules and the nitrate anions are involved in hydrogen bonds to form chains with donor-acceptor distances in the range 2.603-2.969 $\AA$, the lowest intra-chain and inter-chain distances being $10.009 \AA$ and $10.198 \AA$, respectively. 


\section{Magnetic Properties}

The temperature dependence of the $\chi_{M} T$ product for $\mathbf{1}$ is shown in Figure 4 . The room temperature $\chi_{M} T$ value for $\mathbf{1}\left(15.71 \mathrm{~cm}^{3} \mathrm{~K} \mathrm{~mol}^{-1}\right)$ agrees with the expected value for a pair of non-interacting $\mathrm{Gd}^{\mathrm{III}}\left(s_{\mathrm{Gd}}=7 / 2\right)$ ions $\left(15.75 \mathrm{~cm}^{3} \mathrm{~K} \mathrm{~mol}^{-1}\right.$ with $\left.g=2\right)$. On lowering the temperature, $\chi_{M} T$ remains approximately constant to $30 \mathrm{~K}$ and then abruptly increases to reach a value of $21.3 \mathrm{~cm}^{3} \mathrm{~K} \mathrm{~mol}^{-1}$ at $2 \mathrm{~K}$.

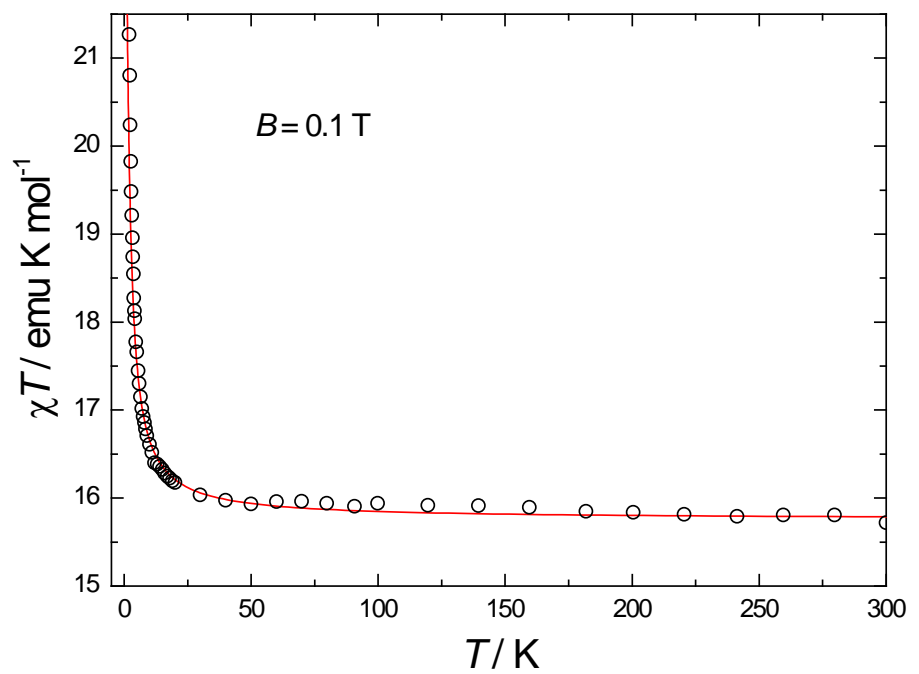

Figure 4. Temperature dependence of the $\chi_{M} T$ product for 1 in the presence of an external magnetic field $B=0.1 \mathrm{~T}$. The solid red line shows the best fit of the experimental data with the Hamiltonian indicated in the text.

This behaviour is due to an intra-dinuclear ferromagnetic interaction between the $\mathrm{Gd}^{\mathrm{III}}$ ions. The magnetic properties have been modelled using the following spin Hamiltonian:

$$
H=-J s_{G d 1} s_{G d 2}+g \mu_{B}\left(s_{G d 1}+s_{G d 2}\right) B
$$


where $J$ is the isotropic exchange interaction, $g$ the g-factor, $\mu_{B}$ the bohr magneton and $B$ the applied magnetic field. The best fit of the experimental susceptibility afforded the following set of parameters: $J=+0.038(2) \mathrm{cm}^{-1}$ and $g_{\mathrm{Gd}}=2.02(4)$. The field dependence of the isothermal magnetization $(M)$ between $2 \mathrm{~K}$ and $10 \mathrm{~K}$ is shown in Figure 5 . The calculated isothermal magnetization curves using the $J$ and $g$ values obtained from fitting the susceptibility data (depicted as dashed lines in Fig. 5) nicely agree with the experimental data (markers).

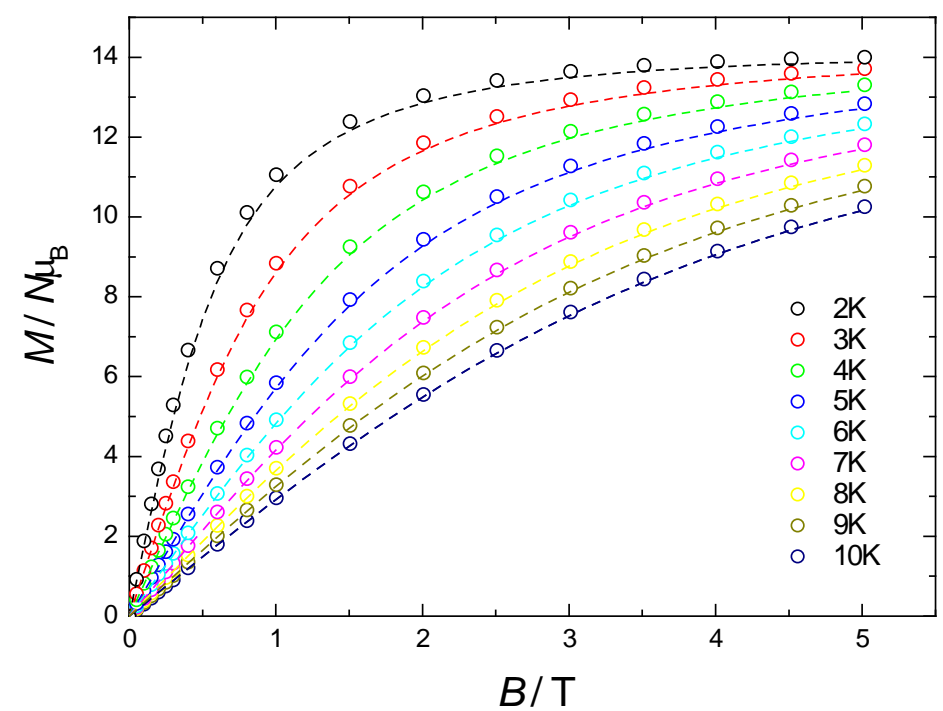

Figure 5.- (Markers) Experimental isothermal magnetization data from $T=2 \mathrm{~K}$ to $10 \mathrm{~K}$, as labeled. (Dashed lines) calculated curves for two $\mathrm{Gd}^{\mathrm{III}}$ ions interacting ferromagnetically with $J$ $=0.038 \mathrm{~cm}^{-1}$.

Figure 6 shows the temperature dependence of the molar heat capacity $(C / R)$ measured in the presence of several magnetic fields. The lattice contribution (dashed line in the top panel), which we associate to vibrational phonon modes, develops at high temperature. Using the Debye model, we have obtained a Debye temperature $\theta_{\mathrm{D}}=36$ 
K, which falls within the range of values usually found for this type of system. ${ }^{19}$ The applied (B) and exchange field participate concomitantly and split the $S=7 / 2$ spin multiplet of each $\mathrm{Gd}^{\mathrm{III}}$ ion, resulting in typical Schottky-like contributions. The exchange is taken into account by considering a local field $B_{\text {loc, }}$ added to $B$. From the best fit of the experimental data (solid lines) we obtain $B_{\text {loc }}=0.28 \mathrm{~T}$. Since $g \mu_{\mathrm{B}} s B_{\mathrm{loc}}=$ $J s^{2}$ (with $s=2 s_{\mathrm{Gd}}$ ) we obtain $J=0.037 \mathrm{~cm}^{-1}$, in perfect agreement with the value found from the fit of the susceptibility.

From the magnetic contribution of the heat capacity, $C_{m}$, obtained by subtracting to $C$ the lattice contribution (dashed line in Fig. 6), we derive the magnetic entropy for $\mathbf{1}$ as a function of temperature and field (Figure 6, bottom) by making use of the equation:

$$
S_{m}(T, B)=\int_{0}^{T} \frac{C_{m}(T, B)}{T} d T
$$

The lack of data in the zero-field heat capacity for temperatures lower than $0.3 \mathrm{~K}$ was corrected by rescaling the experimental entropy such that the high-temperature limit meets the value corresponding to the full magnetic entropy content per mole, i.e., $2 R \ln \left(s_{G d}+1\right)=4.16 R$ for $\mathrm{S}_{G d}=7 / 2$ (dashed line in the bottom panel of figure 6 ). 


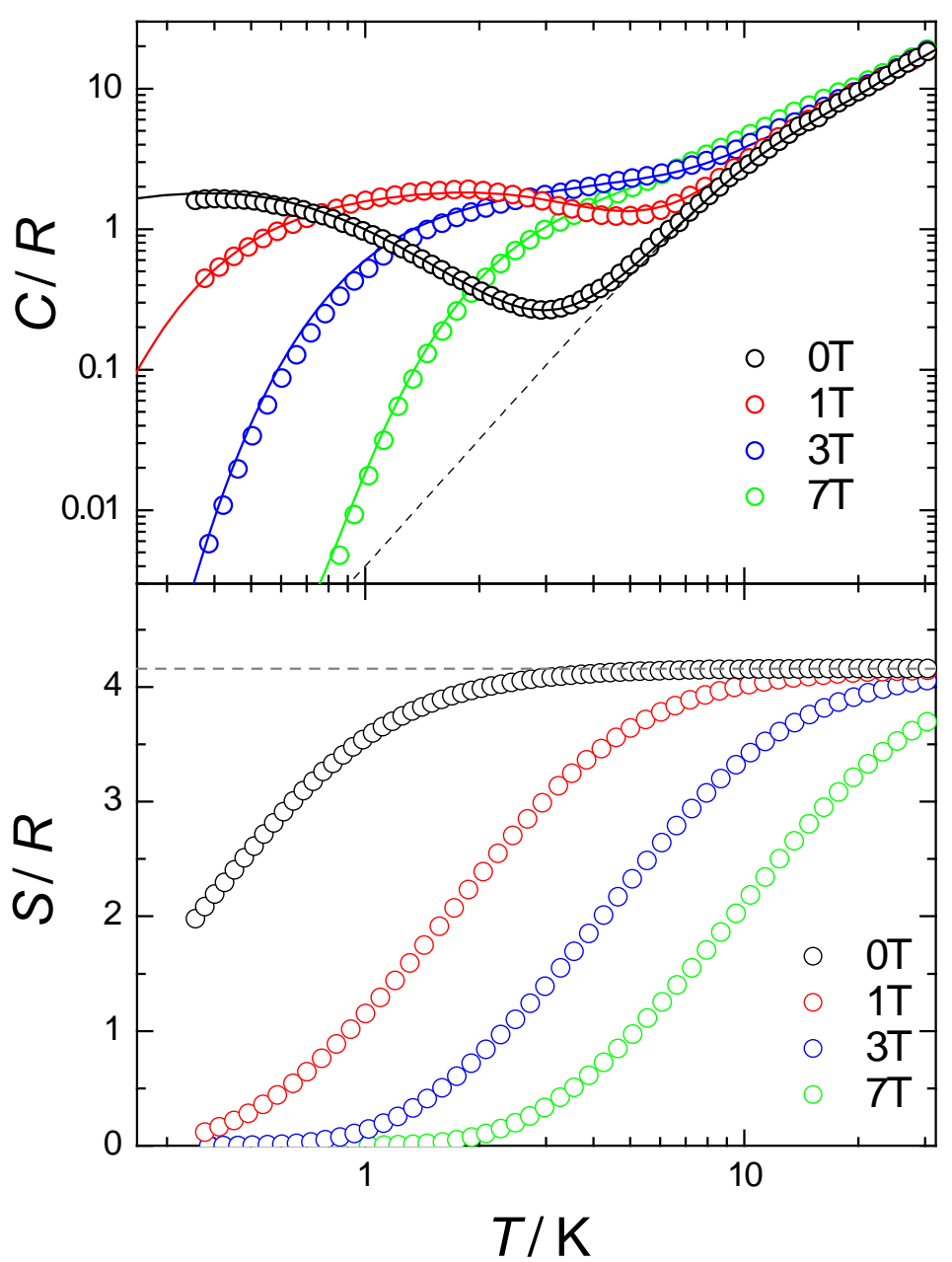

Figure 6. Top: (markers) molar heat capacity for $\mathrm{Zn}_{2} \mathrm{Gd}_{2}$ (1) for several applied magnetic field, as labelled. (Solid lines) theoretical calculations for heat capacity, sum of lattice (dashed line) and magnetic contribution, obtained as explained in the text. Bottom: magnetic entropy obtained from heat capacity data. Dashed line is the limit given by the spin degrees of freedom involved.

From the so-obtained entropy curves we finally calculate the magnetic entropy change, $\Delta S_{\mathrm{m}}$, and adiabatic temperature change, $\Delta T_{\mathrm{ad}}$, respectively, reported in the top and bottom panels of Fig. 7. The $\Delta S_{\mathrm{m}}$ was also estimated from the experimental magnetization data (yellow full markers) by making use of the Maxwell relation:

$$
\Delta S_{m}(T, \Delta B)=\int_{B_{i}}^{B_{f}}\left[\frac{\partial M(T, B)}{\partial T}\right]_{B} d B
$$


The magnetic entropy changes, independently found from heat capacity and magnetization experiments, are in good agreement, thus confirming the validity of our data analyses. The maximum value of $-\Delta S_{\mathrm{m}}$ achieved for $\mathbf{1}$ is $18.5 \mathrm{~J} \mathrm{~kg}^{-1} \mathrm{~K}^{-1}$ at $T=1.9 \mathrm{~K}$ and applied field change $\Delta B=7 \mathrm{~T}$, while $\Delta T_{\text {ad }}$ increases up to $9.6 \mathrm{~K}$ at $T=1.4 \mathrm{~K}$ and $\Delta B$ $=7 \mathrm{~T}$.

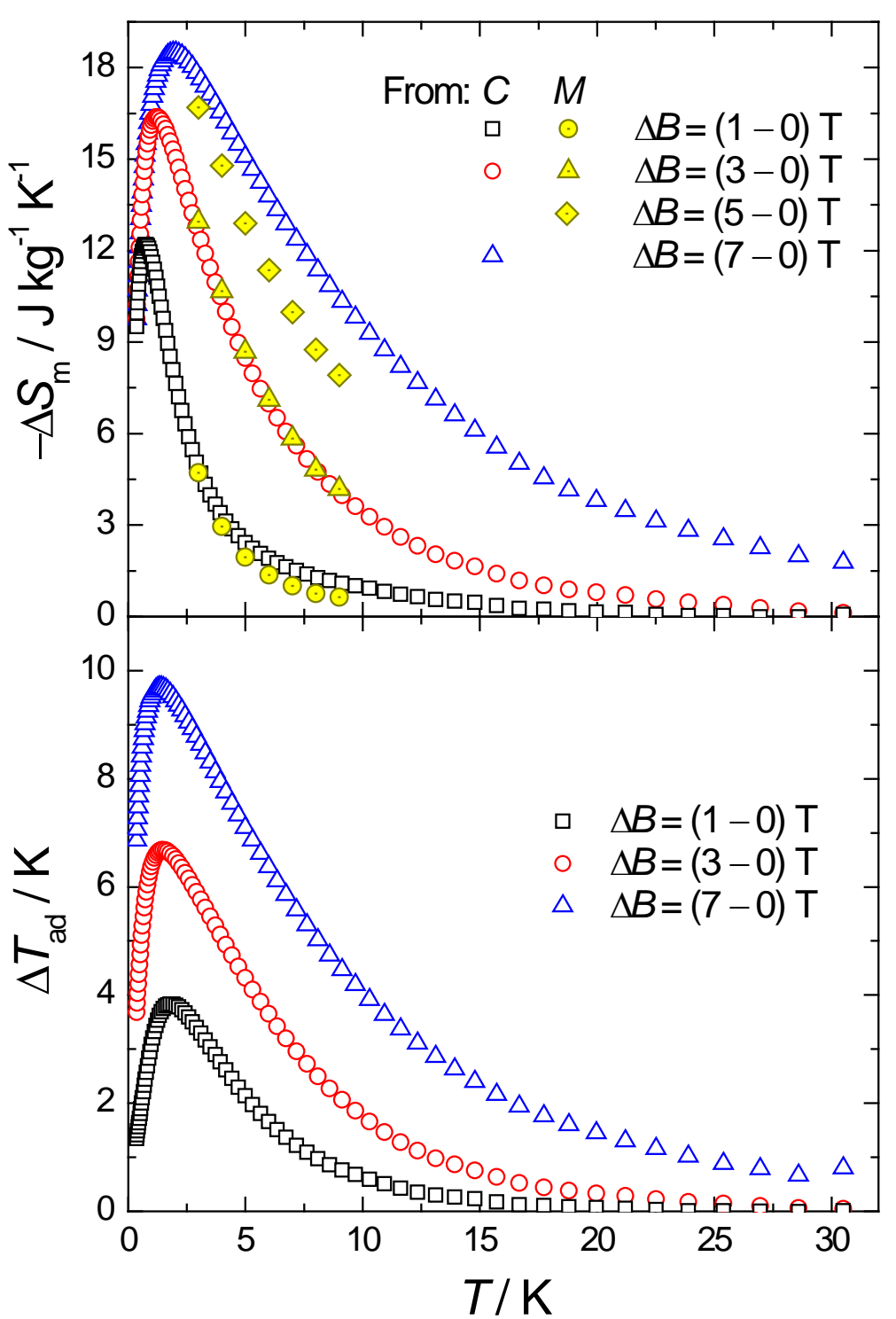


Figure 7. Top: Magnetic entropy change for the labelled magnetic field changes, as obtained from the heat capacity and isothermal magnetization curves. Bottom: adiabatic temperature change for the corresponding labelled magnetic field changes.

The MCE observed for $\mathbf{1}$ is lower than that found for the complex $\left[\left\{\mathrm{Gd}(\mathrm{OAc})_{3}\left(\mathrm{H}_{2} \mathrm{O}\right)_{2}\right\}_{2}\right] \cdot 4 \mathrm{H}_{2} \mathrm{O}^{20}\left(-\Delta S_{\mathrm{m}}=40.6 \mathrm{~J} \mathrm{~kg}^{-1} \mathrm{~K}^{-1}\right.$ for $\left.\Delta B=7 \mathrm{~T}\right)$ that has a similar bridging fragment between the $\mathrm{Gd}^{\mathrm{III}}$ ions, but using acetate instead of carbonate bridging ligands. This is as expected since the MCE is directly correlated to the molar mass, and the former have a much lower magnetic density than the latter. At such large applied fields, sufficient for magnetically decoupling all spin centers, the MCE of Gd ${ }^{\mathrm{III}}$ based complexes is exclusively determined by the values of the molar mass, indeed. ${ }^{9 b}$ For both complexes, the observed maximum $-\Delta S_{\mathrm{m}}$ values are nearly as large as the full entropy content per mole that corresponds to $2 R \ln \left(2 \mathrm{~s}_{\mathrm{Gd}}+1\right)=4.16 R$, which is equivalent to $20.3 \mathrm{~J} \mathrm{~kg}^{-1} \mathrm{~K}^{-1}$ and $42.5 \mathrm{~J} \mathrm{~kg}^{-1} \mathrm{~K}^{-1}$ for $\mathbf{1}$ and $\left[\left\{\mathrm{Gd}(\mathrm{OAc})_{3}\left(\mathrm{H}_{2} \mathrm{O}\right)_{2}\right\}_{2}\right] \cdot 4 \mathrm{H}_{2} \mathrm{O}$, respectively.

The magnetic properties of complexes 2 and 3 are given in the form $\chi_{M} T v s T$ in Figure S3. The room temperature $\chi_{M} T$ values of complexes 2 and 3 are $5.09 \mathrm{~cm}^{3}$ $\mathrm{mol}^{-1} \mathrm{~K}$ and $2.51 \mathrm{~cm}^{3} \mathrm{~mol}^{-1} \mathrm{~K}$, respectively, which are in rather good agreement with the expected theoretical values using the free ion approximation (5.14 and $2.57 \mathrm{~cm}^{3}$ $\mathrm{mol}^{-1} \mathrm{~K}$ ) for two non-interacting $\mathrm{Yb}^{\mathrm{III}}$ ions and one isolated $\mathrm{Yb}^{\mathrm{III}}$ ion, respectively $\left({ }^{7} \mathrm{~F}_{7 / 2}, \mathrm{~S}=1 / 2, \mathrm{~L}=3, \mathrm{~g}=8 / 7\right)$. The $\chi_{M} T$ product for 2 steadily decreases with decreasing temperature to reach a minimum value of $3.48 \mathrm{~cm}^{3} \mathrm{~mol}^{-1} \mathrm{~K}$ at $5 \mathrm{~K}$ and then slightly increases upon cooling to reach $3.56 \mathrm{~cm}^{3} \mathrm{~mol}^{-1} \mathrm{~K}$ at $2 \mathrm{~K}$. The increase below $5 \mathrm{~K}$ could be due either to effect of the crystal field or the presence of a weak ferromagnetic interaction as previously observed for $\mathbf{1}$. For complex 3 , the $\chi_{M} T$ 
product continuously decreases with temperature to reach a value of $1.67 \mathrm{~cm}^{3} \mathrm{~mol}^{-}$ ${ }^{1} \mathrm{~K}$. The decrease is due to the effects of the thermal depopulation of the $m_{J}$ sublevels of the ${ }^{2} \mathrm{~F}_{7 / 2}$ ground multiplet of the $\mathrm{Yb}^{\mathrm{III}}$ ion, as split by the crystal field.

We have tried to model the magnetic properties of $\mathbf{2}$ and $\mathbf{3}$ taking into account the crystal field effects that split the ground ${ }^{2} \mathrm{~F}_{7 / 2}$ term of the $\mathrm{Yb}^{\mathrm{III}}$ Kramers ion in $\mathrm{J}+1 / 2$ doublets and the exchange coupling between the ground doublets. In keeping with the trigonal dodecahedron $\mathrm{D}_{2 \mathrm{~d}}$ local symmetry of the $\mathrm{YbO}_{8}$ coordination environment, the Hamiltonian to be considered is:

$$
H_{C F}=\sum_{i=1}^{2}\left(B_{2}^{0} \boldsymbol{O}_{2}^{\mathbf{0}}+B_{4}^{0} \boldsymbol{O}_{\mathbf{4}}^{\mathbf{0}}+B_{6}^{0} \boldsymbol{O}_{\mathbf{6}}^{\mathbf{0}}+B_{4}^{4} \boldsymbol{O}_{\mathbf{4}}^{\mathbf{4}}+B_{6}^{4} \boldsymbol{O}_{\mathbf{6}}^{\mathbf{4}}\right)-2 J\left(\boldsymbol{J}_{\mathbf{1}}+\boldsymbol{J}_{\mathbf{2}}\right)+\beta g_{j}\left(\boldsymbol{J}_{\mathbf{1}}+\boldsymbol{J}_{\mathbf{2}}\right),
$$

where the first term is the crystal field component expressed as Steven's equivalent operators $\left(\boldsymbol{O}_{\boldsymbol{k}}^{\boldsymbol{q}}\right)$, which are a function of the total angular momentum matrices associated with the ${ }^{2} \mathrm{~F}_{7 / 2}$ term. The second and third terms correspond to the exchange coupling and Zeeman components, respectively. The dc magnetic susceptibility of $\mathbf{1}$ was simulated with the program PHI. ${ }^{21}$ However, the large number of parameters makes it impossible to find a unique solution, even if only the $B_{2}^{0}, B_{4}^{0}$ and $B_{6}^{0}$ CF parameters are considered. Nevertheless, from the different simulations using different CF parameters, with and without consideration of the exchange coupling between the ground doublets, the following conclusions can be drawn: a) the susceptibility data can be simulated by using only $B_{2}^{0}, B_{4}^{0}$ and $B_{6}^{0} \mathrm{CF}$ parameters without considering the exchange between the $\mathrm{Yb}^{\mathrm{III}}$ ions. b) The ground doublet is the $M_{J}= \pm 7 / 2$. The first excited state, $M_{J}= \pm 1 / 2$ being located at an energy $<1 \mathrm{~cm}^{-1}$ above the ground state, with the other two $M_{J}$ states are located at $250 \mathrm{~cm}^{-1}\left(M_{J}= \pm 3 / 2\right)$ and $\sim 410 \mathrm{~cm}^{-1}\left(M_{J}= \pm 5 / 2\right)$. A similar crystal field splitting of the ${ }^{2} F_{7 / 2}$ multiplet has been recently reported for another centrosymmetric dinuclear 
$\mathrm{Yb}^{\mathrm{III}}$ complex with carboxylate bridging ligands that, like 2, exhibits a $\mathrm{YbO}_{8}$ coordination environment in a trigonal dodecahedron geometry and very similar average $\mathrm{Yb}-\mathrm{O}$ distances. ${ }^{12 \mathrm{e}}$

Although the $\mathrm{YbO}_{9}$ coordination environment of $\mathbf{3}$ is rather asymmetric, the dc susceptibility data could be simulated with a high symmetry Hamiltonian that employs just three CF parameters $\left(B_{2}^{0}, B_{4}^{0}\right.$ and $\left.B_{6}^{0}\right)$, leading to a $M_{J}= \pm 7 / 2$ ground state, which is near degenerate with the $M_{J}= \pm 1 / 2$ (the energy separation is $<0.1$ $\left.\mathrm{cm}^{-1}\right)$. The other two $M_{J}$ states would be located at $\sim 240 \mathrm{~cm}^{-1}\left(M_{J}= \pm 3 / 2\right)$ and $\sim 400$ $\mathrm{cm}^{-1}\left(M_{J}= \pm 5 / 2\right)$. The the average Yb-O distances for compound 3 (2.36 $\AA$ ) being slightly larger than that for compound 2 (2.32 $\AA$ ), may be responsible for the weaker crystal field splitting in 3.

UV and NIR luminescence spectra of mononuclear SMMs have been used to determine the energy levels of the $\mathrm{Ln}^{\mathrm{III}}$ ions allowing comparison of these levels to those obtained from magnetic data or $a b$ initio calculations. ${ }^{10 \mathrm{~b}, 12 \mathrm{~d}, \mathrm{e}, 21}$ This methodology has proven to be very useful, particularly in the case of $\mathrm{Dy}{ }^{\mathrm{III}}$ and $\mathrm{Tb}^{\mathrm{III}}$ SMMs. ${ }^{22}$ We have also recently shown that the chromophoric $\mathrm{L}^{2-}$ ligand is able to act as “antenna” group, sensitizing $\mathrm{Ln}^{\mathrm{III}}$-based luminescence through an intramolecular energy transfer to the excited states of the accepting $\mathrm{Ln}^{\mathrm{III}}$ ion. ${ }^{10 a}$, $17 \mathrm{a}$, ${ }^{23}$ In view of this, and with the aim of obtaining the energy gap between the ground and first excited states of compounds $\mathbf{2}$ and 3, we have analyzed the photophysical properties of microcrystalline samples of these complexes at room temperature and $77 \mathrm{~K}$. Excitation of the complexes at $300 \mathrm{~nm}$ and $350 \mathrm{~nm}$, respectively, resulted in the observation of sensitised characteristic $\mathrm{Yb}^{\mathrm{III}}$ emission in the NIR region. It should be noted that the emission spectrum of $\mathbf{2}$ (Figure 8) at both room temperature and $77 \mathrm{~K}$ exhibits three relatively well defined bands at 976, 1008, $1031 \mathrm{~nm}$ and a 
possible weaker feature at ca. $1045 \mathrm{~nm}$.

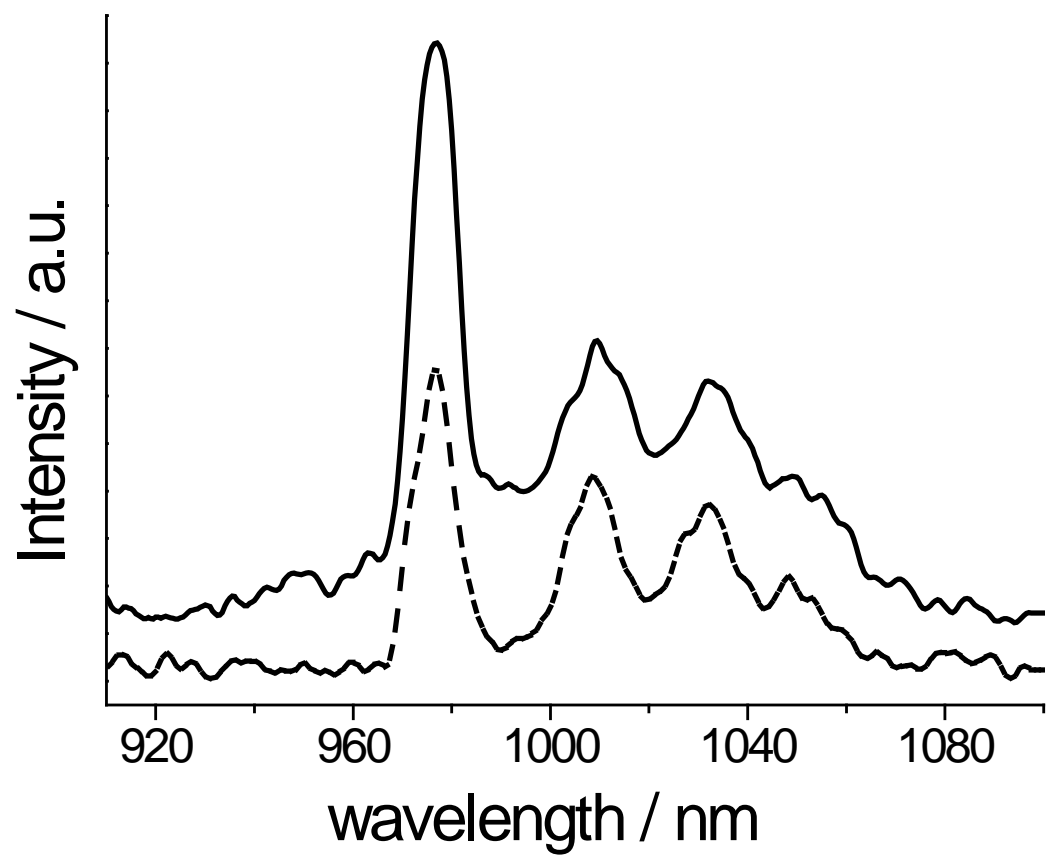

Figure 8.- Solid NIR-emission spectra of $2\left(\lambda_{\text {exc }}=350 \mathrm{~nm}\right)$ at room temperature (solid line) and at $77 \mathrm{~K}$ (dashed line).

It is possible that two different assignments of the above transitions could be made: a) the observed bands may correspond to the four components expected from ${ }^{2} \mathrm{~F}_{5 / 2} \rightarrow{ }^{2} \mathrm{~F}_{7 / 2}$ arising from the ligand field splitting of the ${ }^{2} \mathrm{~F}_{7 / 2}$ multiplet. Although the position of the emission bands and consequently the energy gap between the ground and first excited state $\sim 315 \mathrm{~cm}^{-1}$ and the total splitting $\sim 665 \mathrm{~cm}^{-1}$ are similar to those found for the ytterbium doped $\mathrm{Li}_{6} \mathrm{Y}\left(\mathrm{BO}_{3}\right)_{3}$ compound ${ }^{24}$ (where the $\mathrm{Yb}^{\mathrm{III}}$ ion also exhibits a YbO8 coordination environment), these values are larger than those usually calculated and observed for other $\mathrm{Yb}^{\mathrm{III}} \mathrm{O} 8$ complexes. ${ }^{12}$ In addition to this, an argument against this assignment is that the energy gap between the ground and first excited state would be exceedingly large than the energy gap calculated from the simulation of the $d c$ susceptibility data with the above crystal field Hamiltonian. b) alternatively, the two most energetic transitions are very close in energy and 
appear together as the band at $976 \mathrm{~nm}$. This assignment is more in line with the energy gap calculated from the $d c$ susceptibility data $\left(<2 \mathrm{~cm}^{-1}\right)$ and the total crystal field splitting of the ${ }^{2} \mathrm{~F}_{7 / 2}$ multiplet $\left(550 \mathrm{~cm}^{-1}\right)$ is in agreement with those observed for other $\mathrm{YbO}_{8}$ complexes. ${ }^{12}$ It is worth mentioning that other $\mathrm{YbO}_{8}$ complexes with triangular dodecahedron geometry and similar Yb-O distances do not exhibit the low energy band at $~ 1050 \mathrm{~nm}$ (the other three bands appear at almost the same energies as in the emission spectrum of 2). Although its origin is unclear, the apparent weak band at the lowest energy (1045 nm) could be tentatively attributed, among other things, to the crystal growth process leading to the creation of different $\mathrm{Yb}^{\mathrm{III}}$ defects in the polycrystalline sample, or to a strong interaction of the $\mathrm{Yb}^{\mathrm{III}}$ ion with lattice vibrations, which would result in additional vibronic transition in the spectra, or to local $\mathrm{Yb}^{\mathrm{III}}-\mathrm{Yb}^{\mathrm{III}}$ interactions inducing modifications in the crystal field splitting of the ${ }^{2} \mathrm{~F}_{7 / 2}$ ground multiplet. ${ }^{24}$

In view of the above considerations it would be reasonable to assume that the second assignment (b) is more probable.

The appearance of the room temperature emission spectrum of compound $\mathbf{3}$ shows a well resolved structure (Figure 9). 


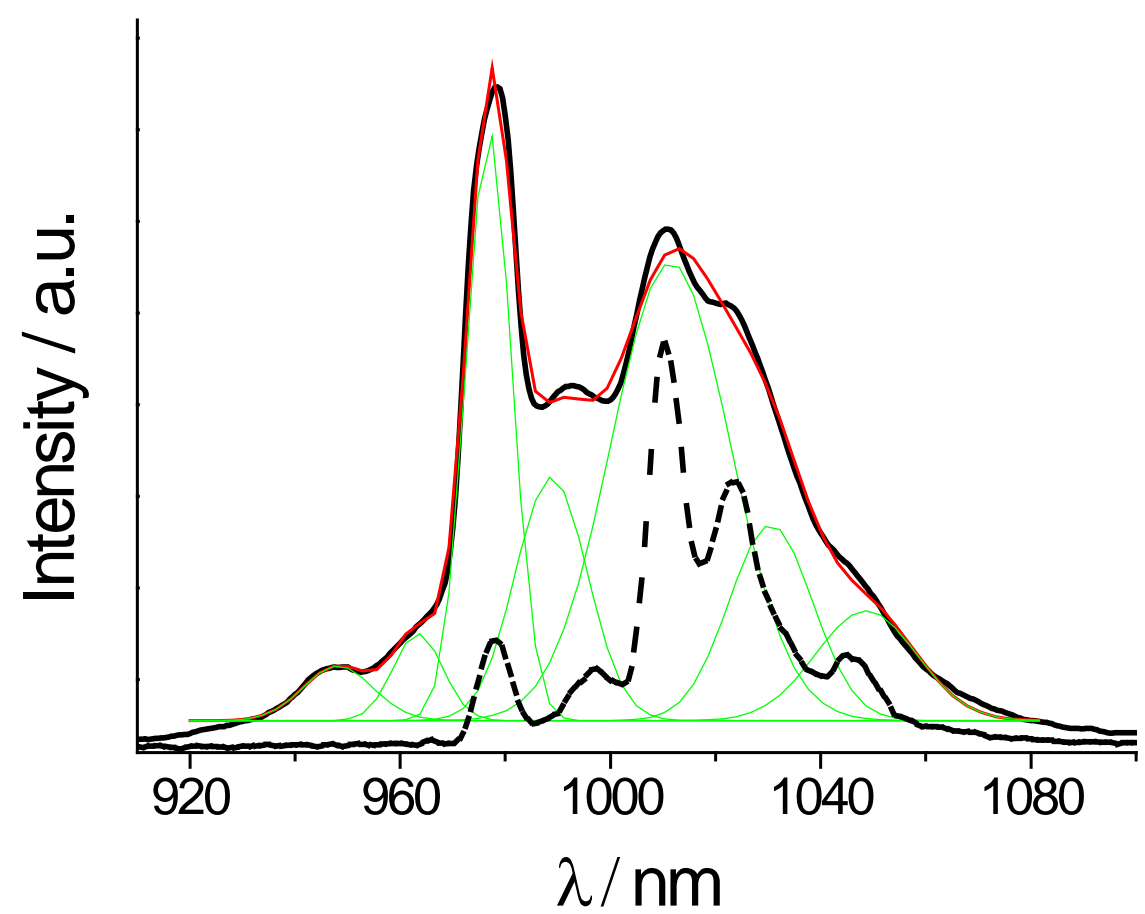

Figure 9.- Solid NIR-emission spectra of $3\left(\lambda_{\text {exc }}=300 \mathrm{~nm}\right)$ at room temperature (black solid line) and at $77 \mathrm{~K}$ (dashed line). Gaussian deconvolution of the room temperature spectrum (green lines) and best fit (red line).

The emission profile can be deconvoluted in to seven bands in the 948-1045 nm range, attributed to the ${ }^{2} \mathrm{~F}_{5 / 2} \rightarrow{ }^{2} \mathrm{~F}_{7 / 2}$ transitions. At $77 \mathrm{~K}$ the high energy bands observed in the room temperature emission spectrum at $948 \mathrm{~nm}$ and $962 \mathrm{~nm}$ disappear and therefore are attributed to "hot" bands, arising from thermally populated high crystal field levels of the ${ }^{2} \mathrm{~F}_{5 / 2}$ state. Although bands at $977 \mathrm{~nm}$ and $992 \mathrm{~nm}$ undergo a decrease in intensity in relation to the lower energy bands, the former is observed in all reported $\mathrm{Yb}^{\mathrm{III}}$ complexes and therefore cannot be considered as a hot band. However, the band at $992 \mathrm{~nm}$ does not usually appear in $\mathrm{Yb}^{\mathrm{III}}$ complexes and when observed is assigned to a "hot" band. ${ }^{12 \mathrm{~d}}$ The remaining bands are assigned as in complex 2, so that the band at $977 \mathrm{~nm}$ encompasses the two more energetic bands whose difference represents the energy gap between the ground and first excited doublets of the ${ }^{2} \mathrm{~F}_{7 / 2}$ ground multiplet. This assignment is 
also in good agreement with the $d c$ magnetic results.

Luminescence decay profiles were satisfactorily fitted with single exponential functions in both cases, thus indicating the existence of only one emissive $\mathrm{Yb}^{\mathrm{III}}$ centre in $\mathbf{2}$ and $\mathbf{3}$, (in $\mathbf{2}$ there are two $\mathrm{Yb}{ }^{\mathrm{III}}$ centres, but they are crystallographically equivalent). The observed luminescence lifetimes $\left(\tau_{\text {obs }}\right)$ are $0.515 \mu$ s and $10 \mu$ s for 2 and 3, respectively. In the case of 2 , the presence of one coordinated water molecule to the $\mathrm{Yb}^{\mathrm{III}}$ centre (and to a lesser extent noncoordinated water molecules) would favour vibrational quenching via $\mathrm{O}-\mathrm{H}$ oscillators, and would be expected to exhibit a relatively shorter lifetime. ${ }^{25}$ In contrast, for complex 3 the effective encapsulation of the metal ion, and thus complete absence of coordinated and non-coordinated solvent molecules, should largely reduce the quenching of the $\mathrm{Yb}^{\mathrm{III}}$ centre and a relatively long lifetime is observed.

Dynamic ac magnetic susceptibility measurements as a function of both temperature and frequency were performed on $\mathbf{2}$ and $\mathbf{3}$. These complexes did not show any out-of-phase ( $\chi_{M}$ ”) signal under zero external field, which can be attributed to the presence of fast relaxation of the magnetization via a QTM mechanism typical of $4 \mathrm{f}$-containing complexes. ${ }^{1}$ When the $a c$ measurements were performed in the presence of a small external $d c$ field of $1000 \mathrm{G}$ to fully or partly suppress the quantum tunneling relaxation of the magnetization, complexes $\mathbf{2}$ and $\mathbf{3}$ showed typical SMM behaviour below $8 \mathrm{~K}$ with out-of-phase peaks in the $5 \mathrm{~K}$ (1488 Hz)-4 K (575 Hz) and $5.5 \mathrm{~K}(1490 \mathrm{~Hz})-3.5 \mathrm{~K}(100 \mathrm{~Hz})$ ranges, respectively (see Figures 9 and 10). Despite the fact that $d c$ fields higher than 1000 Oe do not additionally slow the relaxation of the magnetization, both $\chi_{M}$ ' and $\chi_{M}$ " components (Figure 9 and 10 top) do not go to zero below the maxima at low temperature, which 
can be taken as a clear indication that the quantum tunneling of magnetization has not been efficiently suppressed, which can be promoted by transverse anisotropy, dipolar and hyperfine interactions. Although for Kramers ions, such as $\mathrm{Yb}^{\mathrm{III}}$, the first mechanism would not facilitate the QTM relaxation process, it might be favoured by the mixture of the wavefunction of the ground doublet with that of excited state doublets via the crystal field. ${ }^{26}$
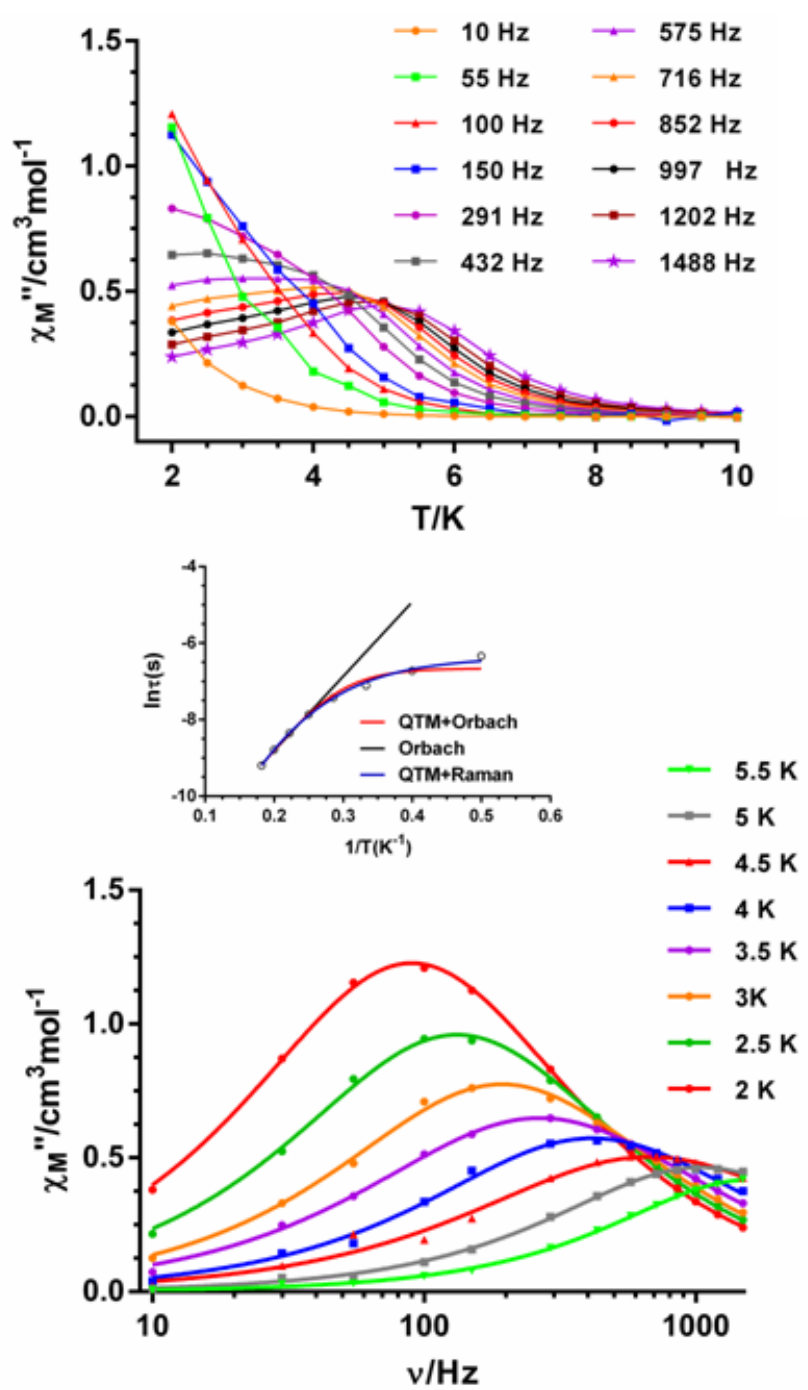

Figure 10.- Temperature dependence of the molar out-of-phase ac susceptibility ( $\chi_{M}$ ”) for 2 under 1000 Oe dc applied field at different frequencies (top). Frequency dependence of the molar out-of-phase ac susceptibility ( $\chi_{M}$ ”) for 2 under 1000 Oe dc applied field at different 
temperatures (bottom). Solid lines represent the best fitting of the experimental data to the Debye model. Inset: Arrhenius plots of relaxation times of 2 under 1 kOe. Black solid lines represent the best fitting of the experimental data to the Arrhenius equation. Red line represents the best fit to a QTM plus Orbach relaxation processes. Blue line represents the best fit to a QTM plus Raman relaxation process.

The Cole-Cole plots (Figure S4 and S5) show in the high temperature regions (6 K-4 K and $5 \mathrm{~K}-4 \mathrm{~K}$ for 2 and 3, respectively) semicircular shapes with $\alpha$ values in the ranges $0.01-0.09$ and $0.03-0.1$ for 2 and 3, respectively, thus indicating the presence of a very narrow distribution of slow relaxation in that region. Below $4 \mathrm{~K}$, the $\alpha$ values undergo a fast increase with decreasing temperature pointing out to the presence of multiple relaxation processes. This is not unexpected as in the low temperature region the fast QTM relaxation process begins to be dominant.

The frequency dependence of $\chi_{M}$ " at each temperature was fitted to the generalized Debye model, which permits the relaxation time $\tau$ to be extracted. The results were then used in constructing the Arrhenius plots for $\mathbf{2}$ and $\mathbf{3}$ which are shown in the insets of Figures 9 and 10. The fit of the high temperature data (above $4 \mathrm{~K}$ and $3.5 \mathrm{~K}$ for 2 and 3, respectively) afforded an effective energy barrier for the reversal of the magnetization of $19.4(7) \mathrm{K}$ with $\tau_{\mathrm{o}}=3.1 \times 10^{-6} \mathrm{~s}$ and $27.0(9) \mathrm{K}$ with $\tau_{\mathrm{o}}=8.8 \times 10^{-7} \mathrm{~s}$, for 2 and $\mathbf{3}$, respectively. The Arrhenius plots, constructed from the temperatures and frequencies of the maxima observed for the $\chi_{M}$ ” signals in Figures 9 and 10 (top), lead to the same results, as expected. As the data deviate from linearity in the low temperature region due to the existence of the QTM relaxation process, we have fitted the temperature dependence of the relaxation time to the following equation that considers the simultaneous occurrence of both the thermal and QTM processes: 


$$
\tau^{-1}=\tau_{Q T}^{-1}+\tau_{0}^{-1} \exp \left(-U_{e f f} / k T\right)
$$

The fit afforded the following parameters: 23.6(9) $\mathrm{K}$ with $\tau_{\mathrm{o}}=1.5 \times 10^{-6} \mathrm{~s}$ and $\tau_{\mathrm{QT}}=$ $0.0013(1) \mathrm{s}$ for 2 and 30(1) K with $\tau_{\mathrm{o}}=5.0 \times 10^{-7} \mathrm{~s}$ and $\tau_{\mathrm{QT}}=0.005(1) \mathrm{s}$. However, the quality of the fit is not perfect, particularly at low temperature (see figures 9 and 10, bottom inset). In view of this we decided to fit the experimental data to an equation that considers that the spin-lattice relaxation takes place through Raman and QTM processes:

$$
\tau^{-1}=B T^{n}+\tau_{Q T}^{-1}
$$

The first term corresponds to the Raman process. In general $n=9$ for Kramers ions, ${ }^{27}$ but depending on the structure of the levels, $n$ values between 1 and 6 can be considered as reasonable. ${ }^{28}$ The fit of the experimental data is excellent affording the following parameters: $\mathrm{n}=4.7(1), \mathrm{B}=3.3(5)$ and $\tau_{\mathrm{QT}}=0.0018(1)$ and $\mathrm{n}=5.9(1), \mathrm{B}$ $=0.35(4)$ and $\tau_{Q T}=0.01(2)$ for 2 and 3, respectively. 

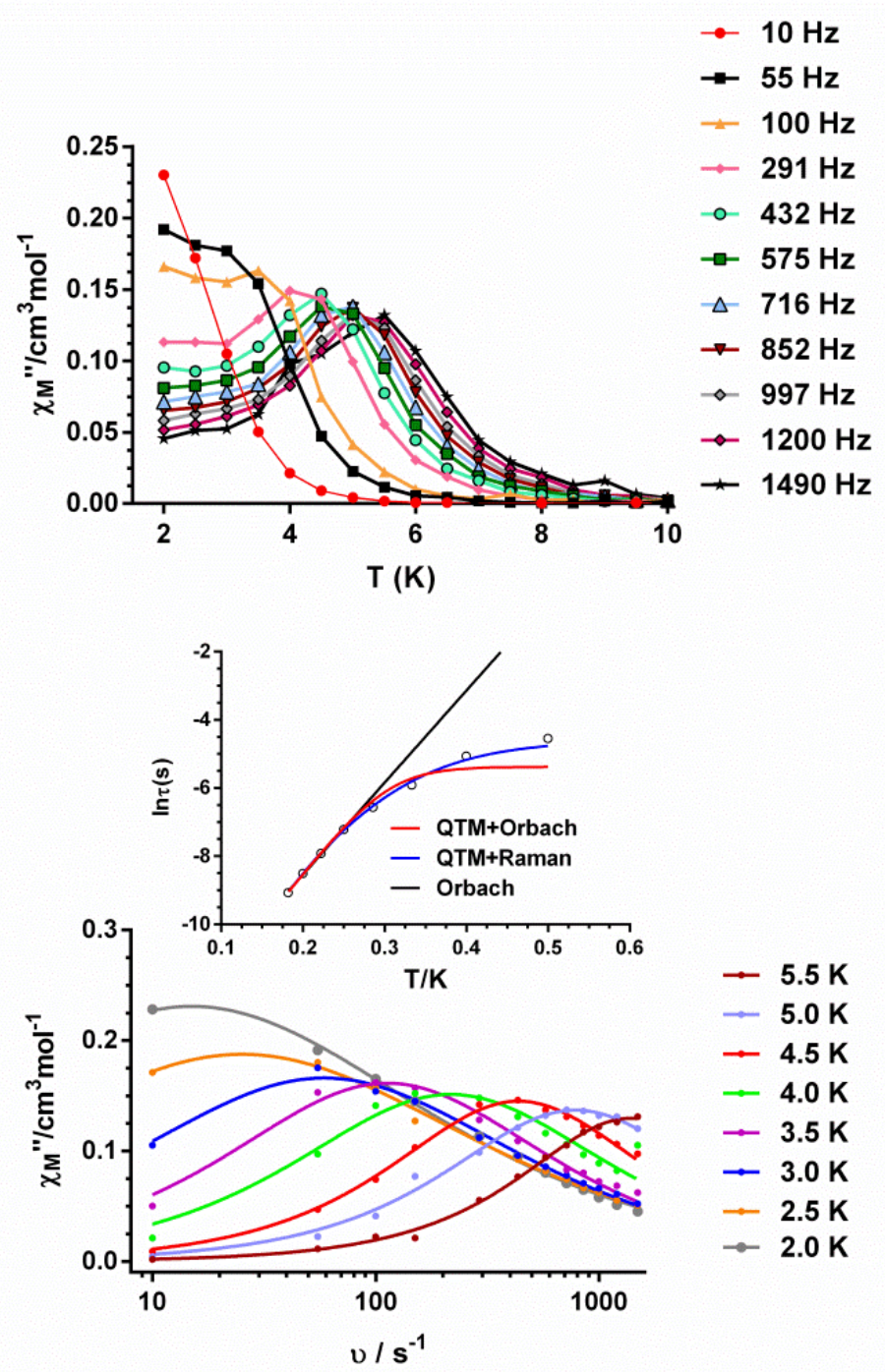

Figure 11.- Temperature dependence of the molar out-of-phase ac susceptibility ( $\chi_{m}$ ") for 3 under 1000 Oe dc applied field at different frequencies (top). Frequency dependence of the molar out-of-phase ac susceptibility ( $\chi_{M}$ ”) for 3 under 1000 Oe dc applied field at different temperatures (bottom). Solid lines represent the best fitting of the experimental data to the Debye model. Inset: Arrhenius plots of relaxation times of $\mathbf{3}$ under 1 kOe. Black solid lines represent the best fitting of the experimental data to the Arrhenius equation. Red line represents the best fit to a QTM plus Orbach relaxation processes. Blue line represents the best fit to a QTM plus Raman relaxation processes. 
The energy barriers extracted for $\mathbf{2}$ and $\mathbf{3}$ from ac dynamic susceptibility measurements are larger than the corresponding energy gap between the ground and first excited doublet states determined by $d c$ susceptibility measurements, which can be due to an underestimation of the energy gaps by the simple crystal field model we used to fit the $d c$ data. Nevertheless, the excellent fit of the ac susceptibility data to a combination of Raman and QTM processes might indicate that the spin-lattice relaxation is not of the thermally activated type, but takes place through an optical acoustic Raman-like process. It should be noted that Raman relaxation processes have previously been proposed for $\mathrm{Yb}^{\mathrm{III}}$ complexes. $^{12}$

\section{Conclusions}

By deliberately designing an $\mathrm{N}_{3} \mathrm{O}_{4}$ compartmental ligand $\left(\mathrm{N}_{3} \mathrm{O}_{2}\right.$-innner site and $\mathrm{O}_{4}$-outer site) we have succeeded in obtaining two closely related $\mathrm{Zn}_{2}{ }_{2} \mathrm{Ln}^{\mathrm{III}}{ }_{2}$ tetranuclear complexes ( $\mathrm{Ln}=\mathrm{Gd}$ and $\mathrm{Yb}$ ), in which two carbonate bridging ligands connect two diphenoxo-bridged $\mathrm{Zn}^{\mathrm{II}} \mathrm{Ln}^{\mathrm{III}}$ units, and a simpler diphenoxo-bridged dinuclear $\mathrm{Zn}^{\mathrm{II}} \mathrm{Yb}^{\mathrm{III}}$ complex. The $\mathrm{Zn}_{2}{ }_{2} \mathrm{Gd}^{\mathrm{III}}{ }_{2}$ complex exhibits a weak ferromagnetic interaction between the $\mathrm{Gd}^{\mathrm{III}}$ ions through the carbonato bridging ligands and a large magneto-caloric effect. The $\mathrm{Zn}_{2}{ }_{2} \mathrm{Yb}^{\mathrm{III}}{ }_{2}$ and $\mathrm{Zn}^{\mathrm{II}} \mathrm{Yb}^{\mathrm{III}}$ complexes show field-induced SMM behaviour, the relaxation of the magnetization on the $\mathrm{Yb}^{\mathrm{III}}$ centers taking place through a Raman-like process rather than through an activated Orbach process. These two compounds are rare examples of $\mathrm{Yb}^{\mathrm{III}}$ containing SMMs. Moreover, both $\mathrm{Zn}^{\mathrm{II}}{ }_{2} \mathrm{Yb}^{\mathrm{III}}{ }_{2}$ and $\mathrm{Zn}^{\mathrm{II}} \mathrm{Yb}^{\mathrm{III}}$ exhibit luminescence in the NIR region, the lifetime being shorter for the former, which is due to the presence of one coordinated water molecule to the $\mathrm{Yb}^{\mathrm{III}}$ centre (and to a lesser extent non-coordinated water molecules) would favor vibrational quenching via $\mathrm{O}-\mathrm{H}$ oscillators. Therefore, the $\mathrm{Zn}_{2}{ }_{2} \mathrm{Yb}^{\mathrm{III}}{ }_{2}$ and $\mathrm{Zn}^{\mathrm{II}} \mathrm{Yb}^{\mathrm{III}}$ reported here can be considered as 
dual magneto-luminescence materials combining NIR emission and filed-induced SMM behaviour.

\section{ASSOCIATED CONTENT}

Elemental analyses for all the complexes, X-ray crystallographic data for 1-3, including data collection, refinement and selected bond lengths and angles. Shape measures, Dc susceptibility data, variable-frequency temperature dependence of the $a c$ in-phase $\chi_{M}$ ' signal and Cole-Cole plots for complexes 2 and 3. This material is available free of charge via the Internet at http://pubs.asc.org.

\section{AUTHOR INFORMATION}

\section{Corresponding Author}

*Email: ecolacio@ugr.es

\section{Notes}

The authors declare no competing financial interest.

\section{ACKNOWLEDGMENTS}

Financial support from the Spanish Ministerio de Ciencia e Innovación (MICINN) and Ministerio de Economía y Competitividad (MINECO) for Projects CTQ-2011-24478 and MAT2012-38318-C03-01, the Junta de Andalucía (FQM-195 and the Project of excellence P11-FQM-7756), and the University of Granada is acknowledged. EKB thanks the EPSRC for funding. GL acknowledges EU for a Marie Curie IEF (PIEF-GA2011-299356). We are grateful to Nuria Clos, Unitat de Mesures Magnètiques Centres Científics i Tecnològics, Universitat de Barcelona, Spain. Technical and human support provided by SGIker (UPV/EHU, MINECO, GV/EJ, ERDF and ESF) for X-Ray measurements is gratefully acknowledged. 


\section{References}

1.- (a) Rinehart, J. D.; Long, J. R. Chem. Sci. 2011, 2, 2078. (b) Sorace, L.; Benelli, C.; Gatteschi, D. Chem. Soc. Rev. 2012, 42, 3278. (c) Luzon, J.; Sessoli, R. Dalton Trans. 2012, 41, 13556. d) Clemente-Juan, J. M.; Coronado, E.; Gaita-Ariño, A. Chem. Soc. Rev. 2012, 41, 7464.

2.- (a) Ward, M. D. Coord. Chem. Rev. 2007, 251, 1663. (b) Binnemans, K. Coord. Chem. Rev. 2009, 109, 4283. (c) Bünzli, J.-C. G. Acc. Chem. Res. 2006, 39, 53. (d) Bünzli, J.-C. G. Acc. Chem. Res. 2006, 39, 53.

3.- Gatteschi, D.; Sessoli R.; Villain J. Molecular Nanomagnets. Oxford University Press. Oxford, UK, 2006.

4.- (a) Evangelisti, M.; Brechin, E. K. Dalton Trans. 2010, 39, 4672. (b) Sessoli, R. Angew. Chem. Int. Ed. 2012, 51, 43. (c) Sharples J. W.; Collison D. Polyhedron 2013, $54,91$.

5.- Bogani, L.; Wernsdorfer, W. Nat. Mat. 2008, 7, 179.

6.- (a) Rocha, A. R.; García-Suárez, V.M.; Bailey, S. W.; Lambert, C. J.; Ferrerand, J.; Sanvito, S. Nat. Mater. 2005, 4, 335. (b) Affronte, M. J. Mater. Chem. 2009, 19, 1731.

7.- (a) Leuenberger, M. N.; Loss, D. Nature 2001, 410, 789. (b) Ardavan, A.; Rival, O.; Morton, J. J. L.; Blundell, S. J.; Tyryshkin, A. M.; Timco, G. A.; Winpenny, R. E. P. Phys. Rev. Lett. 2007, 98, 057201. (c) Stamp, P. C. E.; Gaita-Ariño, A. J. Mater. Chem. 2009, 19, 1718.

8.- (a) Candini, A.; Klyatskaya, S.; Ruben, M.; Wernsdorfer, W.; Affronte, M. Nano Lett. 2011, 11, 2634. (b) Vincent, R.; Klyatskaya, S.; Ruben, M.; Wernsdorfer, W.; 
Balestro, F. Nature 2012, 488, 357. (c) Ganzhorn, M.; Klyatskaya, S.; Ruben M.; Wernsdorfer, W. Nature Nanotech. 2013, 8, 165. (d) Jenkins, M.; Hümmer, T.; Marínez-Pérez, M. J.; García-Ripoll, J.; Zueco, D.; Luis, F. New. J. Phys. 2013, 15, 095007.

9.- (a) Cremades, E.; Gómez-Coca, S.; Aravena, D.; Alvarez S.; Ruiz, E. J. Am. Chem. Soc. 2012, 134, 10532 and references therein. (b) Lorusso, G.; Palacios, M. A.; Nichol, G. S.; Brechin, E. K.; Roubeau, O.; Evangelisti, M. Chem. Commun., 2012, 48, 7592 and references therein. (c) Biswas, S.; Adhikary, A.; Goswami, S.; Konar, S.; Dalton, 2013, 42, 13331. (d) Lorusso, G.; Sharples, J. W.; Palacios, E.; Roubeau, O.; Brechin, E. K.; Sessoli, R.; Rossin, A.; Tuna, F.; McInnes, E. J. L.; Collison, D.; Evangelisti, M. Adv. Mater. 2013, 25, 4653 and references therein.

10.- (a) Ruiz, J.; Herrera, J. M.; Brechin, E. K.; Wersndorfer, W.; Lloret, F.; Colacio, E. Inorg. Chem. 2013, 52, 9620. (b) Ehama, K.; Ohmichi, Y.; Sakamoto, S.; Fujinami, T.; Matsumoto, N.; Mochida, N.; Ishida, T.; Sunatsuki, Y.; Tsuchimoto, M.; Re, N. Inorg. Chem. 2013, 52, 12828. (c) Zhang, P.; Zhang, L.; Lin, S. Y.; Tang, J. Inorg. Chem. 2013, 52, 6595 .

11.- (a) Bünzli, J.-C. G., Chem. Rev. 2010, 110, 2729. (b) Faulkner, S.; Pope, S. J. A.; Burton-Pye, B. P. App. Spect. Rev. 2005, 40, 1. (c) Lin, S. Chem. Soc. Rev. 2004, 33, 445.

12.- (a) Liu, J. L.; Yuan, K.; Leng, J. D.; Ungur, L.; Wernsdorfer, W.; Guo, F. S.; Chibotaru, L. F.; Tong, M. L. 2012, 51, 8538. (b) Lin, P. H.; Sun, W. B.; Tian, Y. M.; Yan, P. F.; Ungur, L.; Chibotaru, L. F.; Mugeresu, M. Dalton Trans. 2012, 41, 12349. (c) Leng, J. D.; Liu, J. L.; Zheng, Y. Z.; Ungur, L.; Chibotaru, L. F.; Guo, F. S.; Tong, M. L. Chem Commun. 2013, 49, 158. (d) Li, Q.W.; Liu, J. L.; Jia, J. H; Leng J. D.; Lin, 
W. Q.; Chen, Y. C.; Tong, M. L. Dalton Trans. 2013, 42, 11262. (e) Pointillart, F.; Le Guennic, B.; Golhen, S.; Cador, O.; Maury, O.; Ouahab, L. Chem. Commun., 2013,49, 615.

13.- (a) Colacio, E.; Ruiz-Sanchez, J.; White, F. J.; Brechin, E. K. Inorg Chem., 2011, 50, 7268.

14.-CrysAlisPro Software System; Agilent Technologies UK Ltd.: Oxford, UK, 2012.

15.- Sheldrick, G.M. SHELXL-97. A Program for Crystal Structure Refinement; University of Göttingen, Germany, 1997.

16.- Farrugia, L. J. J. Appl. Cryst., 1999, 32, 837.

17.- (a) Colacio, E.; Ruiz, J.; Mota, A. J.; Palacios, M. A.; Cremades, E.; Ruiz, E.; White, F. J.; Brechin, E. K. Inorg. Chem. 2012, 51, 5857 (b) Colacio, E.; Ruiz, J.; Mota, A. J.; Palacios, M. A.; Ruiz, E.; Cremades, E.; Hänninen, M. M.; Sillanpää, R.; Brechin, E. K. Comptes Rendus Chimie, 2012, 15, 878.

18.- Llunell, M.; Casanova, D.; Cirera, J.; Bofill, J. M.; Alemany, P.; Alvarez, S.; Pinsky, M.; Avnir, D. SHAPE v1.1b, Barcelona, 2005.

19.- Evangelisti, M.; Luis, F.; de Jongh, L. J.; Affronte, M. J. Mater. Chem. 2006, 16, 2534, and references therein.

20.- Evangelisti, M.; Roubeau, O.; Palacios, E.; Camón, A. ; Hooper, T. N.; Brechin, E. K.; Alonso, J. J. Angew. Chem. Int. Ed. 2011, 50, 6606.

21.- Chilton, N. F.; Anderson, R. P.; Turner, L. D.; Soncini, A.; Murray, K. S. J. Comput. Chem., 2013, 34, 1164. 
22.-(a) Boulon, M.-E.; Cucinotta, G.; Luzon, J.; Degl’Innocenti, V.; Perfetti, M.; Bernot, K.; Calvez, G.; Caneschi, A.; Sessoli, R. Angew. Chem., Int. Ed., 2013, 52, 350. (b) Pointillart, F.; Guennic, B. L.; Cauchy, T.; Golhen, S.; Cador, O.; Maury, O.; Ouahab, L. Inorg. Chem., 2013, 52, 5978. (c) Long, J.; Vallat, R.; Ferreira, R. A. S.; Carlos, L. D.; Almeida Paz, F. A.; Guari, Y.; Larionova, J. Chem. Commun. 2012, 48, 9974. (d) Cucinotta, G.; Perfetti, M.; Luzon, J.; Etienne, M.; Car, P. E.; Caneschi, A.; Calvez, G.; Bernot, K., Sessoli, R. Angew.Chem., Int. Ed., 2012, 51, 1606. (e) Yamashita, K.; Miyazaki, R.; Kataoka, Y.; Nakanishi, T.; Hasegawa, Y.; Nakano, M.; Yamamura, T.; Kajiwara, T. Dalton Trans., 2013,42, 1987.

23.- (a) Ruiz, J.; Mota, A. J.; Rodríguez-Diéguez, A.; Titos, S.; Herrera, J. M.; Ruiz, E.; Cremades, E.; Costes, J. P.; Colacio, E. Chem. Commum. 2012, 48, 7916. (b) Palacios, M. A.; Titos-Padilla, S.; Ruiz, J.; Herrera, J. M.; Pope, S. J.; Brechin, E. K.; Colacio, E. Inorg. Chem., in press.

24.- (a) Sablayrolles; Jubera, V.; Guillen, F.; Decourt, R.; Couzi, M.; Chaminade, J. P.; Garcia, A. Optics Commun. 2007, 280, 103. (b) Jubera, V.; Artamenko, A.; Veber, P.; Velazquez, M.; Garcia, A. Chem. Phys.Chem. 2011, 12, 1288.

25.- Beeby, A., Dickins, R. S.; Faulkner, S.; Parker, D.; Williams J. A. G. Chem. Commun. 1997, 15, 1401.

26.- Baldoví, J. J.; Cardona-Serra, S.; Clemente-Juan, J.; Coronado, E.; Gaita-Ariño, A.; Palii, A. Inorg. Chem. 2012, 51, 12565.

27.- Abragam, A.; Bleaney, B. Electron Paramagnetic Resonance of Transition Ions, Clarendon Press, Oxford, 1970.

28.- Shirivastava, K. N. Phys. Status Solidi B, 1983, 117, 437. 


\section{Supplementary material}

Closely-Related $\mathrm{Zn}^{\mathrm{II}}{ }_{2} \mathrm{Ln}^{\mathrm{III}}{ }_{2}$ complexes $\left(\mathrm{Ln}^{\mathrm{III}}=\mathrm{Gd}, \mathrm{Yb}\right)$ with either Magnetic Refrigerant or Luminescent Single-Molecule Magnet Properties.

José Ruiz, Gulia Lorusso, Marco Evangelisti, Juan Manuel Herrera, Euan K. Brechin, Simon J. Pope, Enrique Colacio. 
Table S1.- Elemental analyses for complexes 1-3.

\begin{tabular}{|c|c|c|c|c|c|c|c|c|}
\hline Compound & Formula & M.W. & $\%$ Cteor & (\% Cexp) & $\%$ Hteor & (\% Hexp) & $\%$ Nteor & (\% Nexp) \\
\hline 1 & $\mathrm{C}_{56} \mathrm{H}_{90} \mathrm{~N}_{8} \mathrm{O}_{24} \mathrm{Zn}_{2} \mathrm{Gd}_{2}$ & 1704.60 & 39.46 & $(39.40)$ & 5.32 & (5.35) & 6.57 & $(6.50)$ \\
\hline 2 & $\mathrm{C}_{56} \mathrm{H}_{98} \mathrm{~N}_{8} \mathrm{O}_{28} \mathrm{Zn}_{2} \mathrm{Yb}_{2}$ & 1808.28 & 37.20 & (37.27) & 5.46 & (5.54) & 6.20 & (6.15) \\
\hline 3 & $\mathrm{C}_{25} \mathrm{H}_{37} \mathrm{~N}_{6} \mathrm{O}_{13} \mathrm{Zn} \mathrm{Yb}$ & 868.02 & 34.52 & $(34.60)$ & 4.30 & $(4.38)$ & 9.68 & $(9.80)$ \\
\hline
\end{tabular}

Table S2.- Crystallographic data for complexes 1-3.

\begin{tabular}{|c|c|c|c|}
\hline Compound & 1 & 2 & 3 \\
\hline Formula & $\mathrm{C}_{56} \mathrm{H}_{90} \mathrm{~N}_{8} \mathrm{O}_{24} \mathrm{Zn}_{2} \mathrm{Gd}_{2}$ & $\mathrm{C}_{56} \mathrm{H}_{98} \mathrm{~N}_{8} \mathrm{O}_{28} \mathrm{Zn}_{2} \mathrm{Yb}_{2}$ & $\mathrm{C}_{25} \mathrm{H}_{37} \mathrm{~N}_{6} \mathrm{O}_{13} \mathrm{ZnYb}$ \\
\hline$M_{r}$ & 1704.60 & 1808.28 & 868.02 \\
\hline Crystal system & Triclinic & Triclinic & Orthorhombic \\
\hline Space group (no.) & $P-1(2)$ & $P-1(2)$ & P212121 (19) \\
\hline$a(\AA)$ & 11.1988(13) & $12.818(5)$ & $10.73183(7)$ \\
\hline$b(\AA)$ & $12.3323(14)$ & $12.963(5)$ & $15.83270(12)$ \\
\hline$c(\AA)$ & 14.2061(16) & $13.031(5)$ & $17.87120(12)$ \\
\hline$\alpha\left(^{\circ}\right)$ & $110.846(2)$ & $62.537(5)$ & 90.00 \\
\hline$\beta\left(^{\circ}\right)$ & $105.310(2)$ & $61.983(5)$ & 90.00 \\
\hline$V\left({ }^{\circ}\right)$ & $99.812(2)$ & $81.114(5)$ & 90.00 \\
\hline$V\left(\AA^{3}\right)$ & $1690.7(3)$ & $1690.7(11)$ & $3036.56(4)$ \\
\hline$z$ & 1 & 1 & 4 \\
\hline$D_{c}\left(\mathrm{~g} \mathrm{~cm}^{-3}\right)$ & 1.674 & 1.768 & 1.899 \\
\hline$\mu\left(\mathrm{MoK}_{\alpha}\right)\left(\mathrm{mm}^{-1}\right)$ & 2.718 & 3.530 & 3.927 \\
\hline$T(\mathrm{~K})$ & $100(2)$ & $100(2)$ & $100(2)$ \\
\hline Observed reflections & 5907 (5551) & 5935 (5663) & $5346(5229)$ \\
\hline$R_{\text {int }}$ & 0.0200 & 0.0300 & 0.0294 \\
\hline Parameters & 444 & 466 & 422 \\
\hline GOF & 1.057 & 1.070 & 1.035 \\
\hline$R_{1}^{a, b}$ & $0.0319(0.0297)$ & $0.0307(0.0294)$ & $0.0177(0.0170)$ \\
\hline$w R_{2}{ }^{\mathrm{c}}$ & $0.0753(0.0737)$ & $0.0793(0.0783)$ & $0.0367(0.0364)$ \\
\hline $\begin{array}{l}\text { Largest difference in } \\
\text { peak and hole }\left(\mathrm{e} \AA^{-3}\right)\end{array}$ & 1.464 and -0.660 & 2.347 and -0.700 & 0.254 and -0.529 \\
\hline
\end{tabular}

a $R_{1}=\Sigma|| \mathrm{F}_{\mathrm{o}}|-| \mathrm{F}_{\mathrm{c}}|| / \Sigma\left|\mathrm{F}_{\mathrm{o}}\right|$.

b Values in parentheses for reflections with $I>2 \sigma(I)$.

${ }^{c} w R_{2}=\left\{\Sigma\left[w\left(F_{o}^{2}-F_{c}^{2}\right)^{2}\right] / \Sigma\left[w\left(F_{o}^{2}\right)^{2}\right]\right\}^{1 / 2}$ 
Table S3.- Selected bond lengths and angles for complexes 1-3.

\begin{tabular}{|c|c|c|c|}
\hline Compound & 1 & 2 & 3 \\
\hline $\operatorname{Ln}(1)-\operatorname{Zn}(1)$ & $3.5094(4)$ & $3.449(1)$ & $3.4382(3)$ \\
\hline $\operatorname{Ln}(1)-\operatorname{Ln}\left(1^{*}\right)$ & $4.0794(4)$ & $3.884(1)$ & \\
\hline $\operatorname{Ln}(1)-O(2 A)$ & $2.467(3)$ & $2.368(3)$ & $2.408(2)$ \\
\hline $\operatorname{Ln}(1)-O(5 A)$ & $2.336(2)$ & $2.282(3)$ & $2.227(2)$ \\
\hline $\operatorname{Ln}(1)-O(25 A)$ & $2.302(2)$ & $2.200(4)$ & $2.176(2)$ \\
\hline $\operatorname{Ln}(1)-O(27 A)$ & $2.564(3)$ & $2.508(3)$ & $2.571(2)$ \\
\hline Ln(1)-O(1B)nitrate & $2.563(4)$ & & $2.435(2)$ \\
\hline Ln(1)-O(2B)nitrate & $2.491(4)$ & & $2.421(2)$ \\
\hline Ln(1)-O(1C)nitrate & & & $2.415(2)$ \\
\hline $\operatorname{Ln}(1)-\mathrm{O}(2 \mathrm{C})$ nitrate & & & $2.366(2)$ \\
\hline $\operatorname{Ln}(1)-\mathrm{O}(2 \mathrm{C})$ carbonate & $2.435(2)$ & $2.327(3)$ & \\
\hline $\operatorname{Ln}(1)-\mathrm{O}\left(2 \mathrm{C}^{*}\right)$ carbonate & $2.385(3)$ & $2.302(3)$ & \\
\hline $\operatorname{Ln}(1)-\mathrm{O}\left(3 \mathrm{C}^{\star}\right)$ carbonate & $2.421(2)$ & $2.323(5)$ & \\
\hline Ln(1)-O(2D)bridge & & & $2.412(2)$ \\
\hline $\operatorname{Ln}(1)-O(1 W)$ & & $2.290(2)$ & \\
\hline $\mathrm{Zn}(1)-\mathrm{N}(12 \mathrm{~A})$ & $2.204(4)$ & $2.205(4)$ & $2.179(2)$ \\
\hline $\mathrm{Zn}(1)-\mathrm{N}(16 \mathrm{~A})$ & $2.207(5)$ & $2.194(4)$ & $2.194(2)$ \\
\hline $\mathrm{Zn}(1)-\mathrm{N}(20 \mathrm{~A})$ & $2.287(4)$ & $2.285(5)$ & $2.237(3)$ \\
\hline $\mathrm{Zn}(1)-\mathrm{O}(5 \mathrm{~A})$ & $2.177(2)$ & $2.187(4)$ & $2.167(2)$ \\
\hline $\mathrm{Zn}(1)-\mathrm{O}(25 \mathrm{~A})$ & $2.122(2)$ & $2.133(3)$ & $2.043(2)$ \\
\hline $\mathrm{Zn}(1)-\mathrm{O}(1 \mathrm{C})$ carbonate $^{\mathrm{a}}$ & $2.037(3)$ & $2.052(2)$ & $2.158(2)$ \\
\hline $\operatorname{Ln}(1)-O(5 A)-Z n(1)$ & $102.0(1)$ & 101.0(1) & 102.96(8) \\
\hline $\operatorname{Ln}(1)-O(25 A)-Z n(1)$ & $104.9(1)$ & $105.5(1)$ & 109.12(9) \\
\hline $\operatorname{Ln}(1)-O(2 C)-\operatorname{Ln}\left(1^{\star}\right)$ & $115.6(1)$ & $114.0(1)$ & \\
\hline$O(5 A)-\operatorname{Ln}(1)-O(25 A)$ & $71.90(9)$ & 73.2(1) & $70.82(7)$ \\
\hline$O(5 A)-\operatorname{Ln}(1)-O(2 C)^{b}$ & $74.18(8)$ & $76.0(1)$ & $76.23(7)$ \\
\hline$O(25 A)-\operatorname{Ln}(1)-O(2 C)^{b}$ & $73.22(9)$ & $78.0(1)$ & $79.40(7)$ \\
\hline $\mathrm{O}(2 \mathrm{C})-\operatorname{Ln}(1)-\mathrm{O}\left(2 \mathrm{C}^{\star}\right)$ & $64.38(8)$ & $66.0(1)$ & \\
\hline$O(5 A)-Z n(1)-O(25 A)$ & $78.57(9)$ & $76.4(1)$ & $74.53(8)$ \\
\hline$O(5 A)-Z n(1)-O(1 C)^{c}$ & $94.8(1)$ & $95.7(1)$ & $87.43(8)$ \\
\hline$O(25 A)-Z n(1)-O(1 C)^{c}$ & $91.8(1)$ & $90.5(1)$ & $90.69(8)$ \\
\hline
\end{tabular}

a En 3, O(1D) bridge

${ }^{b}$ En 3, O(2D) bridge

c En 3, O(1D) bridge 
Table S4.- Continuous Shape Measures calculations for complexes 1-3.

\section{Compound 1}

MFF-9

13 Cs Muffin

HH-9

$12 \mathrm{C} 2 \mathrm{v}$ Hula-hoop

JTDIC-9

$11 \mathrm{C} 3 \mathrm{v}$ Tridiminished icosahedron J63

TCTPR-9

10 D3h Spherical tricappedtrigonal prism

JTCTPR-9

9 D3h Tricappedtrigonal prism J51

CSAPR-9

JCSAPR-9

CCU-9

$8 \mathrm{C} 4 \mathrm{v}$ Spherical capped square antiprism

$7 \mathrm{C} 4 \mathrm{v}$ Capped square antiprism J10

JCCU-9

$6 \mathrm{C} 4 \mathrm{v}$ Spherical-relaxed capped cube

JTC-9

$5 \mathrm{C} 4 \mathrm{v}$ Capped cube J8

HBPY -9

4 C3v Johnson triangular cupola J3

OPY -9

3 D7h Heptagonal bipyramid

EP-9

$2 \mathrm{C} 8 \mathrm{v}$ Octagonal pyramid

$1 \mathrm{D} 9 \mathrm{~h}$ Enneagon

MFF-9 HH-9 JTDIC-9 TCTPR-9 JTCTPR-9 CSAPR-9 JCSAPR-9

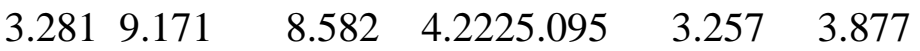

CCU-9 JCCU-9 JTC-9 HBPY-9 OPY-9 EP-9

$\begin{array}{lllll}6.707 & 7.779 & 15.178 & 14.976 & 22.154\end{array}$

Compound 3

\begin{tabular}{|c|c|c|c|c|c|}
\hline MFF-9 & НH-9 & JTDIC-9 & TCTPR-9 & JTCTPR-9 & CSAPR-9 \\
\hline 1.579 & 11.211 & 10.8182 .260 & 4.329 & 1.450 & 2.429 \\
\hline CCU-9 & JCCU-9 & JTC-9 & HВРY-9 & OPY-9 & EP-9 \\
\hline 7.863 & 9.212 & 14.985 & 7.691 & 251 & \\
\hline
\end{tabular}

Compound 2

ETBPY-8 13 D3h Elongated trigonalbipyramid

TT-8 12 Td Triakis tetrahedron

JSD-8 11 D2d Snub diphenoid J84

BTPR-8 $\quad 10 \mathrm{C} 2 \mathrm{v}$ Biaugmentedtrigonal prism

JBTPR-8 9 C2v Biaugmentedtrigonal prism J50

JETBPY-8 8 D3h Johnson elongated triangular bipyramid J14

JGBF-8 7 D2d Johnson gyrobifastigium J26

TDD-8 6 D2d Triangular dodecahedron

SAPR-8 5 D4d Square antiprism

CU-8 4 Oh Cube

HBPY-8 3 D6h Hexagonal bipyramid

HPY-8 2 C7v Heptagonal pyramid

OP-8 1 D8h Octagon

ETBPY-8 TT-8 JSD-8 $\quad$ BTPR-8 JBTPR-8 JETBPY-8 JGBF-8

$\begin{array}{lllllll}21.148 & 9.516 & 4.091 & 3.018 & 4.051 & 26.019 & 13.734\end{array}$

TDD-8 SAPR-8 CU-8 HBPY-8 HPY-8 OP-8

$\begin{array}{llllll}1.548 & 3.784 & 8.828 & 14.043 & 22.977 & 31.652\end{array}$ 


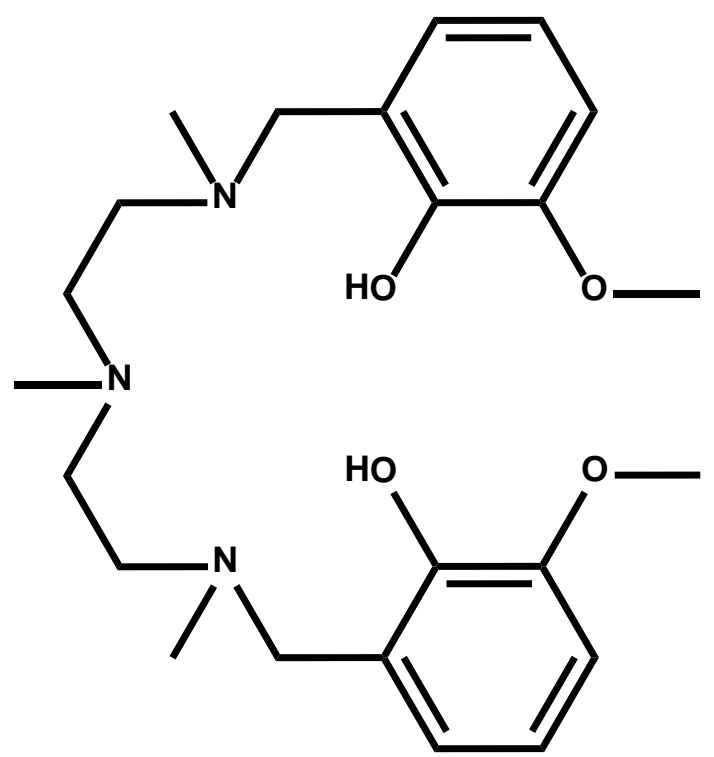

Figure S1.- Structure of the $\mathrm{H}_{2} \mathrm{~L}$ ligand.

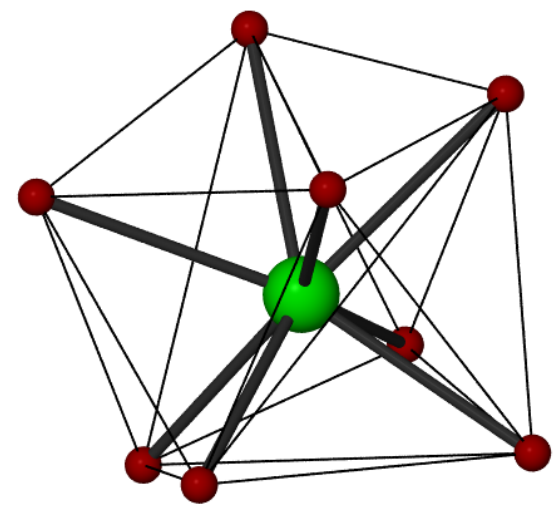

Figure S2.- YbO8 coordination environment in compound 2. 


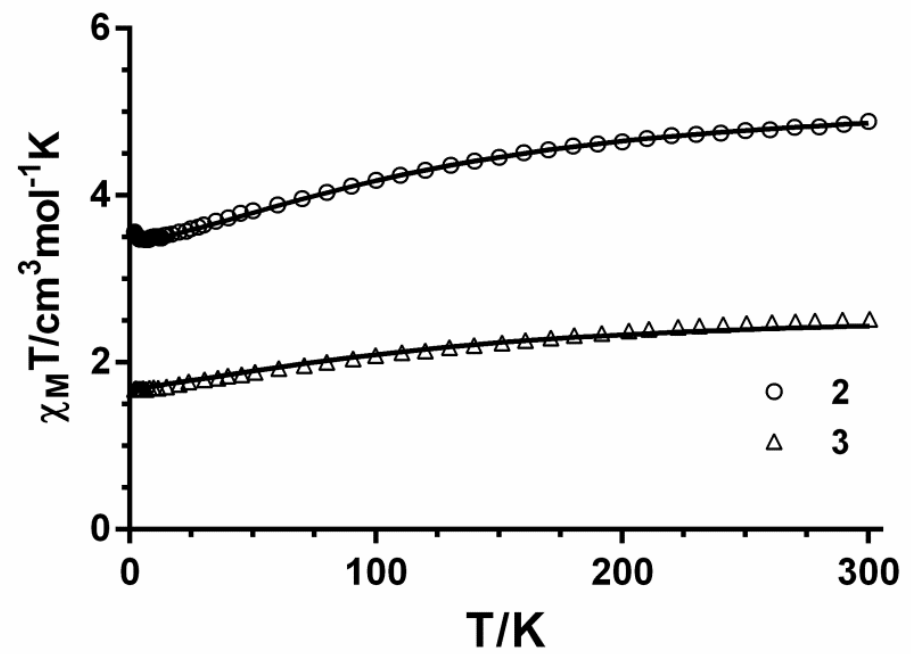

Figure S3.- Temperature dependence of the CMT product for $\mathbf{2}$ and 3. Solid lines represent the fits with $B_{2}^{0}, B_{4}^{0}$ and $B_{6}^{0}$ of $1.335 \mathrm{~cm}^{-1},-0.335 \mathrm{~cm}^{-1}$ and $0.00089 \mathrm{~cm}^{-1}$ for 2 and $1.276 \mathrm{~cm}^{-1},-0.328 \mathrm{~cm}^{-1}$ and $0.00088 \mathrm{~cm}^{-1}$ for 3 .

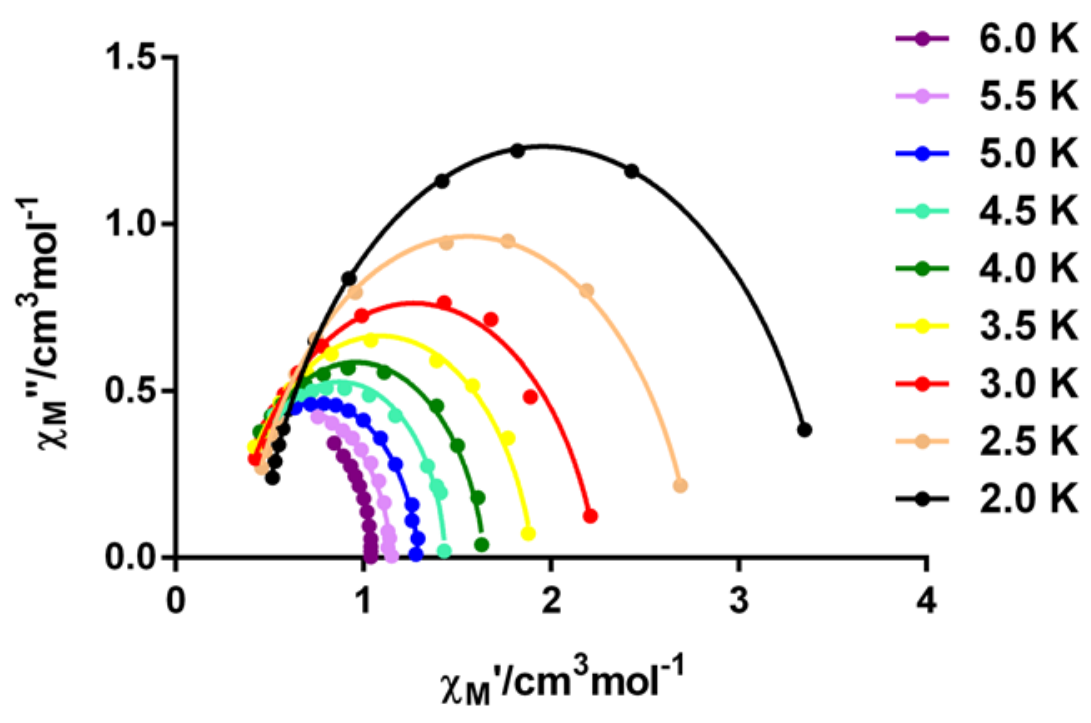

Figure S4.- Cole-Cole plot for complex 2. 


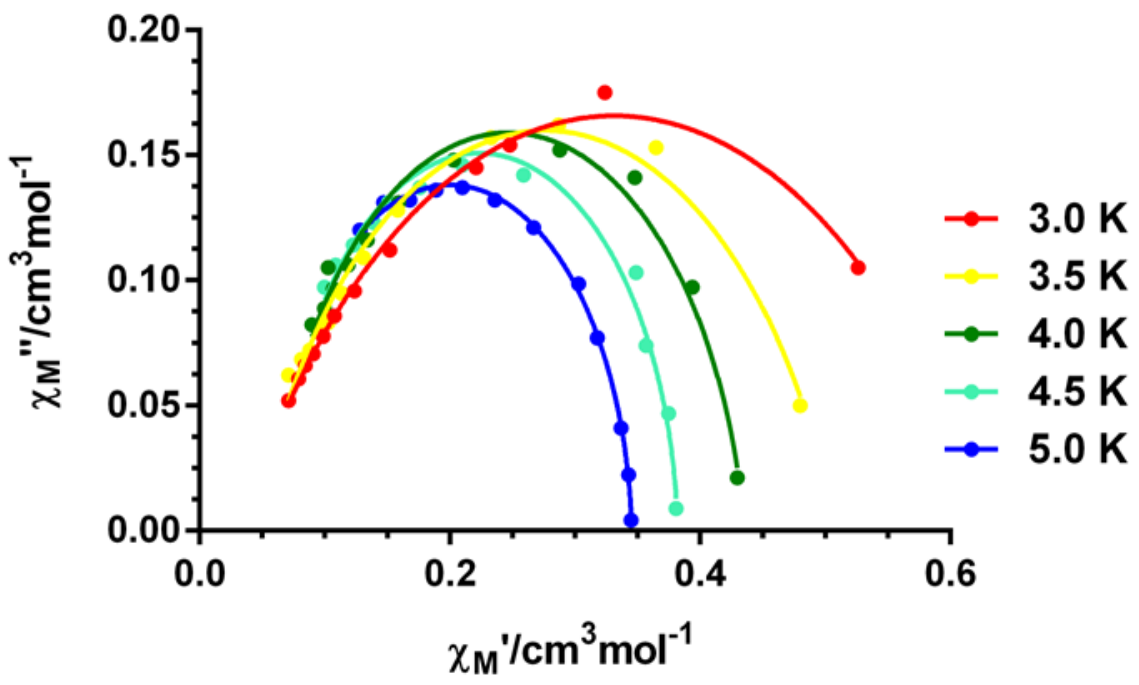

Figure S5.- Cole-Cole plot for complex 3.

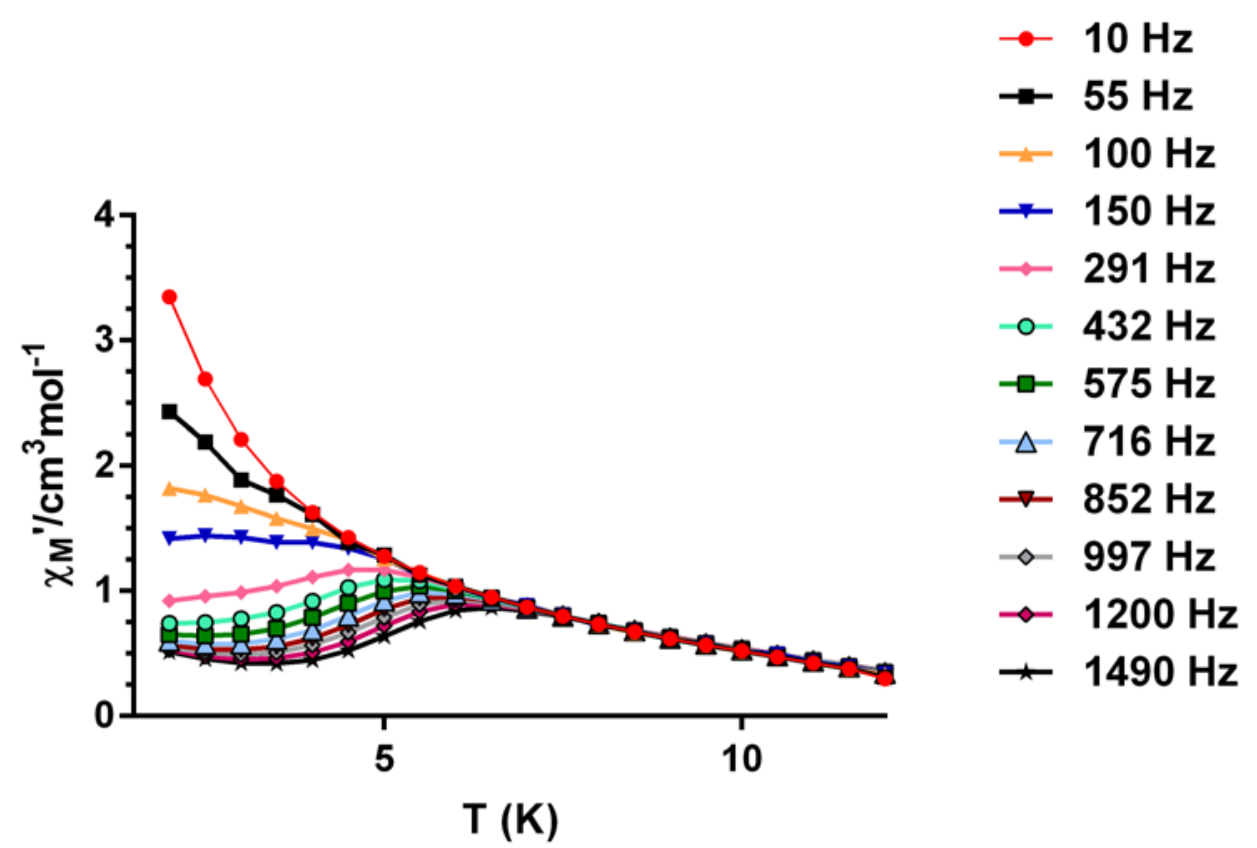

Figure S6.- Temperature dependence of the molar in-phase ac susceptibility ( $\chi_{M}$ ') for $\mathbf{2}$ under 1000 Oe dc applied field at different frequencies. 


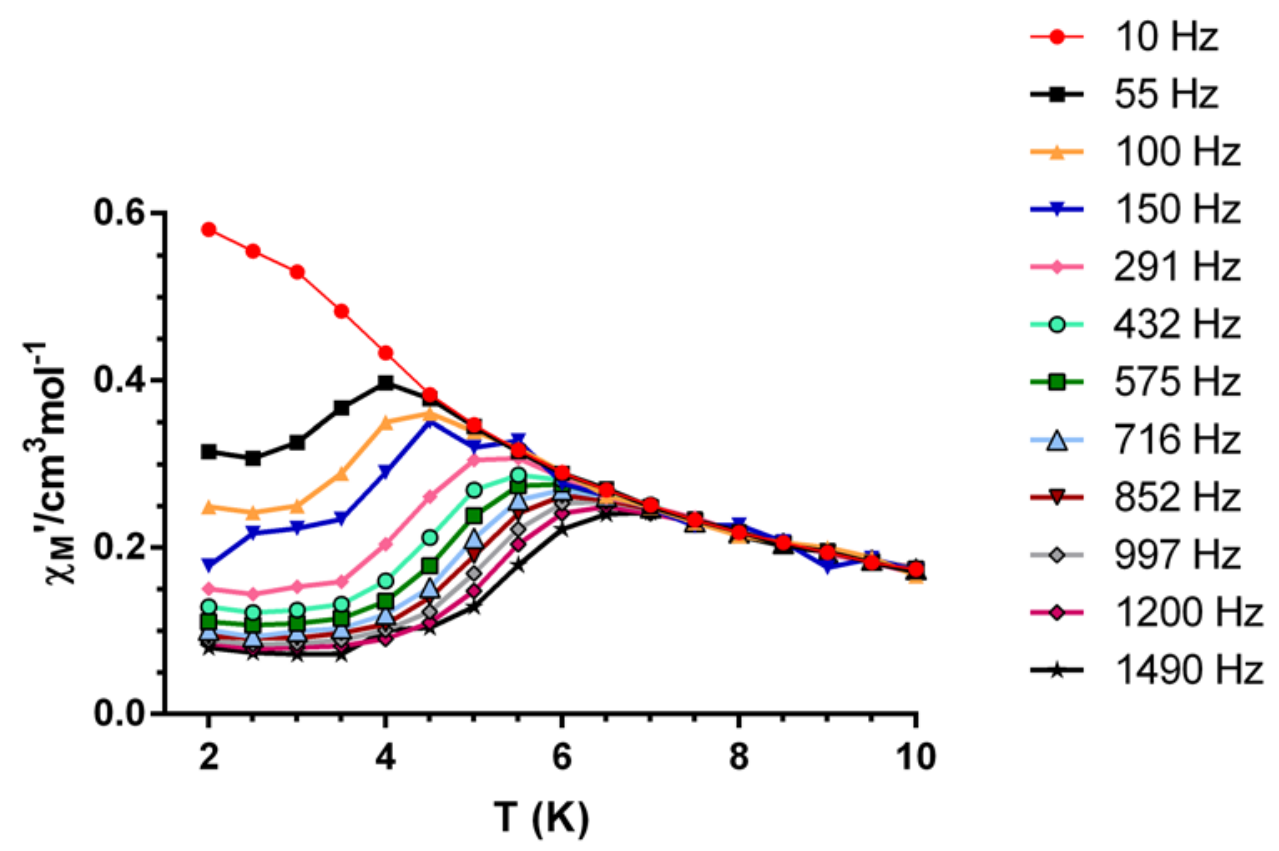

Figure S7.- Temperature dependence of the molar in-phase ac susceptibility ( $\left.\chi_{M}{ }^{\prime}\right)$ for $\mathbf{3}$ under 1000 Oe dc applied field at different frequencies. 